\title{
System Noise Assessment of Blended-Wing-Body Aircraft with Open Rotor Propulsion
}

\author{
Yueping Guo* \\ Boeing Research \& Technology, Huntington Beach, CA 92647 \\ and \\ Russell H. Thomas ${ }^{\dagger}$ \\ NASA Langley Research Center, Hampton, VA 23681
}

\begin{abstract}
An aircraft system noise study is presented for the Blended-Wing-Body (BWB) aircraft concept with three open rotor engines mounted on the upper surface of the airframe. It is shown that for such an aircraft, the cumulative Effective Perceived Noise Level (EPNL) is about $24 \mathrm{~dB}$ below the current aircraft noise regulations of Stage 4. While this makes the design acoustically viable in meeting the regulatory requirements, even with the consideration of more stringent noise regulations of a possible Stage 5 in the next decade or so, the design will likely meet stiff competitions from aircraft with turbofan engines. It is shown that the noise levels of the BWB design are held up by the inherently high noise levels of the open rotor engines and the limitation on the shielding benefit due to the practical design constraint on the engine location. Furthermore, it is shown that the BWB design has high levels of noise from the main landing gear, due to their exposure to high speed flow at the junction between the center body and outer wing. These are also the reasons why this baseline BWB design does not meet the NASA N+2 noise goal of $42 \mathrm{~dB}$ below Stage 4 . To identify approaches that may further reduce noise, parametric studies are also presented, including variations in engine location, vertical tail and elevon variations, and airframe surface acoustic liner treatment effect. These have the potential to further reduce noise but they are only at the conceptual stage.
\end{abstract}

\section{Nomenclature}

$\begin{array}{ll}\text { AOA } & =\text { angle of attack } \\ \text { ANOPP } & =\text { Aircraft Noise Prediction Program } \\ \text { BPF } & =\text { blade passage frequency } \\ \text { BPR } & =\text { engine bypass ratio, mass flow of fan to mass flow of core } \\ \text { BWB } & =\text { Blended-Wing-Body, Boeing specific design } \\ D & =\text { rotor diameter } \\ d B & =\text { decibel } \\ \text { ERA } & =\text { NASA's Environmentally Responsible Aviation Project } \\ E P N L & =\text { effective perceived noise level, decibels } \\ H W B & =\text { Hybrid Wing Body, generic term } \\ L S A F & =\text { Low Speed Aeroacoustic Facility, Boeing } \\ \text { MCP } & =\text { Modular Component Prediction } \\ \mathrm{N}+2 & =\text { NASA terminology for aircraft technology entering service in } 2025 \\ \text { PNLT } & =\text { tone corrected perceived noise level, decibels } \\ S P L & =\text { sound pressure level }\end{array}$

\footnotetext{
* Technical Fellow, Acoustics Technology, 5301 Bolsa Ave, Huntington Beach, CA, AIAA Associate Fellow, Current Address: NEAT Consulting, 3830 Daisy Circle, Seal Beach, CA 90740

${ }^{\dagger}$ Senior Research Engineer, Aeroacoustics Branch, MS 461, AIAA Senior Member 


\section{Introduction}

Open rotor propulsion is believed to be fuel efficient in comparison with turbofan engines, and thus, has attracted much attention, in general, and particularly during periods when the cost of aviation fuel has increased noticeably. Its practical implementation faces many technical and regulatory challenges, one of which is its noise. Open rotor noise mostly consists of annoying tones that are not attenuated, due to the lack of engine nacelle casing, and thus, freely propagate to the far field (Ref 1-3). Before the latest generation of open rotor designs, it is known that aircraft of conventional tube-and-wing design with open rotor propulsion would have difficulties in meeting the noise regulations. Design technologies in recent years have improved the acoustic characteristics of open rotors so that they are projected to meet the noise regulations, but only with limited margins, and thus, still have a competitive disadvantage to turbofan engines. For example, the most current open rotor designs may have a cumulative Effective Perceived Noise Level (EPNL) of about 13 decibels below the noise regulations of Stage 4 (Ref 4) for a tail mounted tube-and-wing configuration, which is less attractive, for the noise metric, than turbofan engines that can give a cumulative EPNL between 15 to 20 decibels below Stage 4. With the concept of a Hybrid Wing Body or Blended-Wing-Body (BWB) aircraft, however, this noise disadvantage may be overcome by the shielding of the engine noise by the airframe body, due to the design of mounting the engines above the airframe. This design feature, of course, benefits both open rotor and turbofan engine applications with the BWB (Ref 5-9), but considering that noise may be a roadblock in practical use of open rotor engines, it is especially of interest to assess the acoustics benefit of such designs for open rotor propulsion, and this is the objective of the study reported here.

In this study, a detailed assessment will be given on the system noise of a BWB aircraft design with open rotor propulsion. Both the airframe and the open rotor engine designs, resulting from a comprehensive study (Ref 10), follow practical design principles to ensure the feasibility of realistic applications. The designs, however, also include advanced technologies that are not fully mature now but are in active development and are expected to mature and enter service in the next decade or so, in the timeframe of NASA's N+2 definition. Thus, the design both satisfies practical feasibility, in aircraft configuration as well as in aircraft operational procedures, and incorporates emerging technologies. It is important for aircraft system noise assessment to be based on realistic configurations because achieving noise goals is never the only or the main objective of aircraft design. Instead, many other important factors such as propulsion efficiency and aerodynamic performance must be prioritized in the design process in order to meet various mission requirements. Obviously, the noise assessment would be irrelevant without the practical constraints in aircraft design, because without the constraints of practical feasibility, any noise goal would be achievable, by artificially and unrealistically lowering the flight speed and engine power, for example, which would allow the noise to be reduced to any arbitrarily low levels according to the fundamental theory of aerodynamic sound (Ref 11) that predicts the noise as an increasing function of speed and engine power.

The configuration studied here is a design of a BWB with open rotor propulsion that is most likely to be technically feasible in the timeframe of the next 10 to 15 years. For this configuration, it will be shown that the aircraft can achieve a cumulative EPNL level about $24 \mathrm{~dB}$ below the current noise regulations of Stage 4, a comfortable margin to the current aircraft noise regulations, and to the potentially more stringent regulations in the next decade or so, which makes the configuration acoustically viable in meeting current and anticipated noise regulations. The low noise levels largely result from the shielding effects of the BWB airframe. It is, however, not necessarily a significant competitive advantage over conventional designs with turbofan engines. The latest generations of aircraft in service, such as the Boeing 787 and the Airbus 380, already have cumulative EPNL margins to Stage 4 on the order of 16 to $20 \mathrm{~dB}$. This margin can be expected to increase for future aircraft that are in active development, helped both by better high lift system design and by more advanced turbofan engines. It is also obvious that the noise margin of $24 \mathrm{~dB}$ for this baseline BWB configuration is far from the NASA N+2 noise goal of $42 \mathrm{~dB}$ below Stage 4 . There are various reasons for this, including the inherently high levels of the open rotor engine sources in comparison with turbofan engines, the high levels of the airframe noise due to the main landing gear, and the limitation on the shielding benefit dictated by the engine locations near the trailing edges of the airframe. However, this BWB configuration is chosen to represent a design that is most likely to be viable in the NASA N+2 timeframe leading to the conclusion that further significant development is necessary for the open rotor powered BWB aircraft in order to achieve the NASA N+2 noise goals and to make the BWB/open rotor design a viable commercial product.

To identify the challenges and technologies for further noise reduction, parametric studies will be presented to demonstrate the impact of various design changes on the total aircraft noise. These include the variations in the engine locations that have a direct impact on the noise shielding efficiency, the local design features such as vertical 
tails and trailing edge elevons that may enhance the BWB noise shielding, and the concept of acoustic liner treatment on the BWB airframe surface to absorb the acoustic wave impinging on the surfaces. It will be shown that these concepts all have the potential to reduce noise, and the noise reduction will be quantified as a function of the design parameters. However, it is important to emphasize that some of the concepts are only in their early stage of research, and some may not be feasible or favorable in aircraft design even when the technologies are mature, because of their potential adverse impact on aircraft performance. For example, engine locations upstream of the BWB trailing edges further than one rotor diameter would significantly enhance noise shielding, but could unacceptably degrade the aerodynamic propulsion integration. Vertical tails located next to the engines are considered beneficial to sideline noise shielding, but they may cost extra fuel for the added weight, possibly by as much as 3 percent. Aircraft weight and fuel cost are critical design criteria, and the trade between a few $\mathrm{dB}$ of noise reduction and a few percent of fuel cost would be considered only if the gain in noise reduction is absolutely necessary either in meeting regulatory requirements or for competitive reasons. A companion paper by Thomas et al (Ref 12) presents a system noise assessment considering the impact of a similar range of possible noise reducing options and technologies to provide a technical roadmap for how a BWB with open rotor propulsion might reduce its total aircraft noise further and might achieve the NASA N+2 noise goal.

\section{Baseline Configuration}

The baseline configuration of the BWB design results from a comprehensive design study (Ref 10), following the best practice in aircraft design as well as incorporating potential technologies that are likely to mature in the next decade or so, namely, in the 2025 entry-into-service timeframe of NASA's N+2 goals. This allows the design to be practically feasible, to meet various mission requirements, and to achieve a good balance between various factors such as fuel savings and aerodynamic performance. The configuration is the baseline BWB design with three open rotors mounted on the upper surface of the airframe structure, as illustrated in Figure 1. The design details that affect the acoustic characteristics of the aircraft will be described when discussing the various noise components, while the basic features of the design are summarized in Table 1.

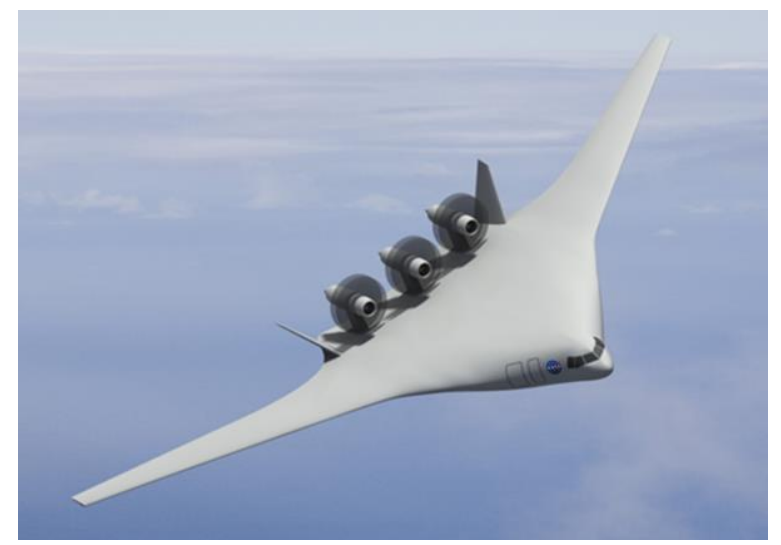

Figure 1. BWB configuration with open rotor engines.

An important parameter in engine noise shielding by the BWB airframe is the locations of the engines. For the baseline configuration, the design puts the center of the two-stage rotors at 94 percent of a rotor diameter $(D)$ upstream of the BWB trailing edge. For maximum shielding efficiency, it is intuitive that the engines should be as far away from the edges of the airframe as possible. This is, however, constrained by the design requirements of aerodynamic performance and propulsion efficiency. The upper side of the lifting body is designed to have high speed flows at cruise conditions. The intrusion of engines into this high speed flow region would destroy the flow pattern and severely degrade the aerodynamic performance of the aircraft. The high speed flow into the engine rotors would also decrease the propulsion efficiency. In addition, the weight balance of the aircraft due to the engines and their supporting structures is also a design feature to be considered. These factors dictate the design that has to ensure the mission requirements. For the baseline configuration, the design study reported in Ref 10 has shown that the engines cannot be placed more than $1 D$ upstream of the trailing edge, in order to avoid severe interference with the high speed flows at cruise. In fact, an engine location of about $0.75 \mathrm{D}$ upstream of the trailing edge would pose much less challenges for the aero-propulsion integration. The $0.94 D$ location has already pushed the aero-propulsion integration to the design envelope, in order to maximize the acoustic benefit. It should also be 
noted that this design guideline applies not only to open rotor engines but also turbofan engines, which is why the engine locations for the various aircraft concepts studied in Ref 10 are all within $1 D$ from the trailing edge.

Table 1. Characteristics of baseline BWB design.

\begin{tabular}{lcc}
\hline \multicolumn{1}{c}{ Parameter } & Unit & Value \\
\hline Maximum Takeoff Weight & $\mathrm{lb}$ & 419848 \\
Cruise Mach Number & - & 0.85 \\
Wing Span & $\mathrm{ft}$ & 229.3 \\
Reference Wing Area & $\mathrm{ft}^{2}$ & 8048 \\
Wing Aspect Ratio & - & 5.62 \\
Reference Thrust & $\mathrm{lb}$ & 138000 \\
Number of Engines & - & 3 \\
Engine Diameter D & in & 182 \\
Engine Position to BWB Trailing Edge & $D$ & 0.94 \\
\hline
\end{tabular}

The use of vertical tails in BWB aircraft design is an issue that has not been satisfactorily resolved. They are thought to be helpful in stability control, but are often included in the design in the hope of acoustic benefit; it is intuitive that the vertical tails can block some of the noise in the sideline direction. While the limited data available have not been able to conclusively demonstrate the acoustic benefit of the vertical tails, their added weight and the cost of aerodynamic performance has been a concern. It has been estimated that up to 3 percent of fuel cost would be needed to have the verticals. Thus, it becomes really questionable whether the fuel cost is worth the potential acoustic benefit. For this reason, the vertical tails will not be included in the baseline configuration for the acoustic assessment (even though they are included in Figure 1 for illustration purpose). Instead, their effects on the total aircraft noise will be discussed as an optional design feature whose utilization will depend on the balance between the potential acoustic benefit and the benefit/penalty on other design parameters.

Another noise reduction concept that is not included in the baseline configuration is surface liner treatment. This is a proven technology for tone dominated noise, as is the case for open rotor engines, mostly applied inside engine casings. The lack of engine casing for the open rotors naturally leads to the idea of utilizing the airframe surfaces in the vicinity of the engine installation to deploy liners to attenuate the noise from the rotors before it propagates to the far field. The obstacle for this application, however, is the induced drag; the airframe surfaces are all exposed to the external aerodynamic flows, and hence, all require minimum drag. It is not clear at this time how much additional drag the liner treatment will induce. If it turns out to be materially non-negligible, the critical step for developing this technology for this application would be a drag-less, or minimum-drag, liner design. For this reason, the surface liner treatment is considered an early-stage technology for future development, and it is excluded from the baseline configuration because it is now only at the proof-of-concept stage.

Similar care must also be exercised in defining baseline technologies for airframe noise reduction. In the past two decades or so, there has been extensive research in developing noise reduction technologies for airframe noise components, including concepts such as cove filler and sealed gap for slats (Ref 13,14), fences and continuous mold line for flap side edges (Ref 15 - 17), and fairings of various kinds for landing gears (Ref 18 - 20). None of the concepts, however, has made its way to current production aircraft. Considering the long lead time needed to develop and mature technologies in aircraft industry, this does not necessarily mean that none of the concepts will eventually be viable for practical applications, but it is instructive and helpful to examine the obstacles that have prolonged the transition of these concepts to reality. These obstacles include the added weight to the aircraft, a carefully watched criterion in aircraft design, the cost of implementation and maintenance, and the lack of robustness in noise reduction. Some of these may be resolved in the next decade or so, but not all of them. For the baseline BWB configuration considered here, slat noise reduction is considered in the form of Krueger slats and sealed slat gap, which would likely mature in the form of hinged Krueger slats without gaps. Other technologies are also feasible, which seal the slat gaps at normal operation conditions but open up the gap at extreme conditions when maximum lift is required. These projected technologies make the BWB slat noise very low, in comparison with other noise components, as will be seen in later sections, because the Krueger slats efficiently reduce the cove noise and the sealed gaps effectively eliminate the gap noise. Technologies for reducing landing gear noise are also expected to be available in the next 10 to 15 years, and thus, some are included in the baseline configuration here. The technologies may be in the form of local fairings, redesign of the gear parts, and overall fairings, all of which 
have been actively researched in recent years. In the next decade or so, local fairings and component redesign are most likely to become mature enough for practical applications.
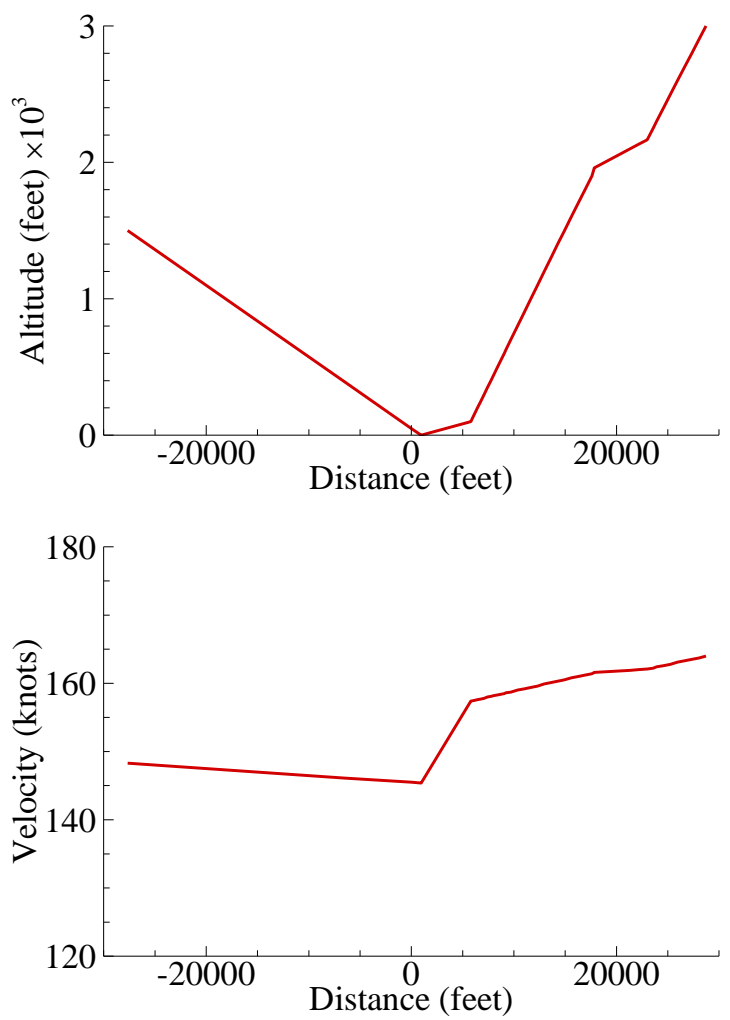

Figure 2. Flight altitude (upper) and velocity (lower) for the BWB aircraft acoustic analysis.

In aircraft system noise assessment, flight operational conditions play an important role, because the flight parameters such as the flight Mach number and the aircraft angle of attack determine the noise source levels and the flight path determines the distance of the noise propagation, and hence, the amplitude of the noise received at the measurement locations. Similarly to aircraft design, flight procedures must also follow practical requirements, set by regulatory rules for safety and/or by airport authorities for operation efficiency. For example, current airport practice requires an aircraft to approach for landing at a 3 degree flight path angle. Following rules such as this, the flight profile for the baseline configuration is designed and illustrated in Figure 2 for all three conditions of aircraft noise certification, with the upper diagram plotting the flight altitude as a function of the touchdown distance, and the lower diagram plotting the flight velocity. The three noise certification conditions are all shown in the figures as conventionally done; the first segment represents the approach condition with decreasing altitude and velocity, the short second segment is for ground operation, the third segment with increasing altitude and velocity represents normal takeoff when the sideline noise is measured, and the fourth segment is for engine power cutback operations with reduced climb rate.

Table 2. Flight parameters at noise certification conditions.

\begin{tabular}{c|ccc}
\hline & Approach & Cutback & Sideline \\
\hline Altitude (ft) & 400 & 2099 & 1000 \\
Speed (knot) & 146.1 & 161.9 & 159.4 \\
AOA (deg) & 11.06 & 12.65 & 12.26 \\
Thrust (lb) & 3087 & 46590 & 95064 \\
\hline
\end{tabular}

While it is not obvious from the flight altitude shown in the upper diagram of Figure 2 how the flight profile differs from that of conventional aircraft operations, the velocity profile in the lower diagram clearly illustrates one 
of the features of the BWB design; it has better lift characteristics so that it can take off and land at lower velocities. For example, the approach velocity of 146 knots for the BWB is probably about 10 to 15 knots lower than the velocity of a comparable conventional aircraft. This feature will also clearly manifest itself in the aircraft angle of attack and its total engine thrust, respectively shown in the upper and lower diagram of Figure 3, for the three noise certification conditions. For conventional aircraft, the angle of attack at takeoff and landing operations is usually in the range between 4 to 8 degrees. For the BWB aircraft, it can be as high as 12 degrees. Because of the lower flight velocity and higher angle of attack, the BWB aircraft can supply a large amount of lift, reducing the requirement for engine power, especially at approach conditions. For example, the total engine thrust of about $3000 \mathrm{lb}$ for the BWB to land is about one quarter of what is required for a conventional aircraft of comparable size. These have direct acoustic effects; the low flight velocity leads to low airframe noise and the low engine thrust corresponds to less engine noise, which will all be included in the noise assessment presented in later sections. The flight conditions are also summarized in Table 2.
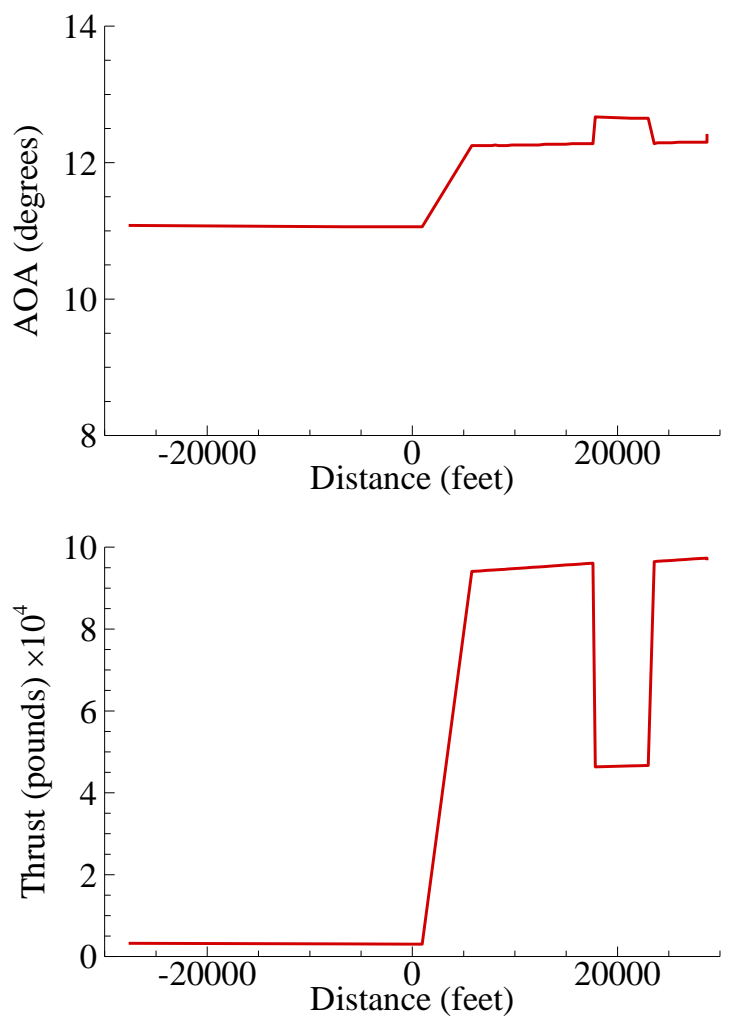

Figure 3. Aircraft angle of attack (upper) and engine thrust (lower) for the BWB aircraft acoustic analysis.

\section{Analysis Methodology}

While there are commonly used and validated tools for system noise assessment of conventional aircraft configurations, such as the NASA tool package Aircraft Noise Prediction Program (ANOPP) and the Boeing inhouse tool Modular Component Prediction (MCP), acoustic tools for advanced aircraft configurations such as BWB are still in the development stage. Predictions of open rotor engine noise currently rely heavily on very limited data with strong empirical nature, and the empirical engine noise tools are mostly stand-alone and are not incorporated in system noise assessment tools. For engine noise shielding by the airframe structures, though much effort has been made to develop prediction tools in recent years, these tools are largely in development, some of which are still to be validated and others are limited by their heavy computation resource requirements. Thus, noise shielding for full configuration aircraft can only be dealt with on the empirical basis by utilizing wind tunnel tests data, which is also a stand-alone process outside any system noise prediction tool package.

Thus, it is of interest to describe the process used in the study presented here for system noise analysis, which is a combination of empirical prediction, component modeling and local feature numerical computation. The process is illustrated in Figure 4, consisting of the following elements. The acoustic analysis process starts with the design specifications, including the design of the airframe structure, engine type and power setting, and flight profiles. The 
design specifications are the basis for the noise component source level analysis for both the propulsion system and the airframe structure, and the flight profiles determine the operation conditions at the noise certification points. From the aircraft design, propulsion system definitions are used to establish the engine noise source levels for all major engine noise components. For open rotor engines, they contain tones from the front rotor, the rear rotor, and the interactions between the two, and the broadband noise component of the rotor system. The component source levels also include those of the airframe structures, namely, the landing gears, the leading edge slats, and the trailing edge elevons. The component noise source levels are for individual, isolated components, which need to be assembled under the constraints of the particular aircraft configuration to take into account of the inter-component interactions and shielding. This is a major feature of the BWB configuration where the engine noise may be significantly shielded by the airframe structure, effectively reducing the effects of source levels on the far field radiation. Far field noise can also be significantly affected by local flow changes, which are configuration dependent, such as the landing gear locations. The far field noise from all the components is assembled into the total aircraft noise on an energy basis, meaning that the acoustic energies from all the components are summed together incoherently without considering the potential acoustic interactions between the components in the far field. The far field total noise levels are then used to compute the standard noise metrics, such as the Tone Corrected Perceived Noise Level (PNLT) and the Effective Perceived Noise Level (EPNL).

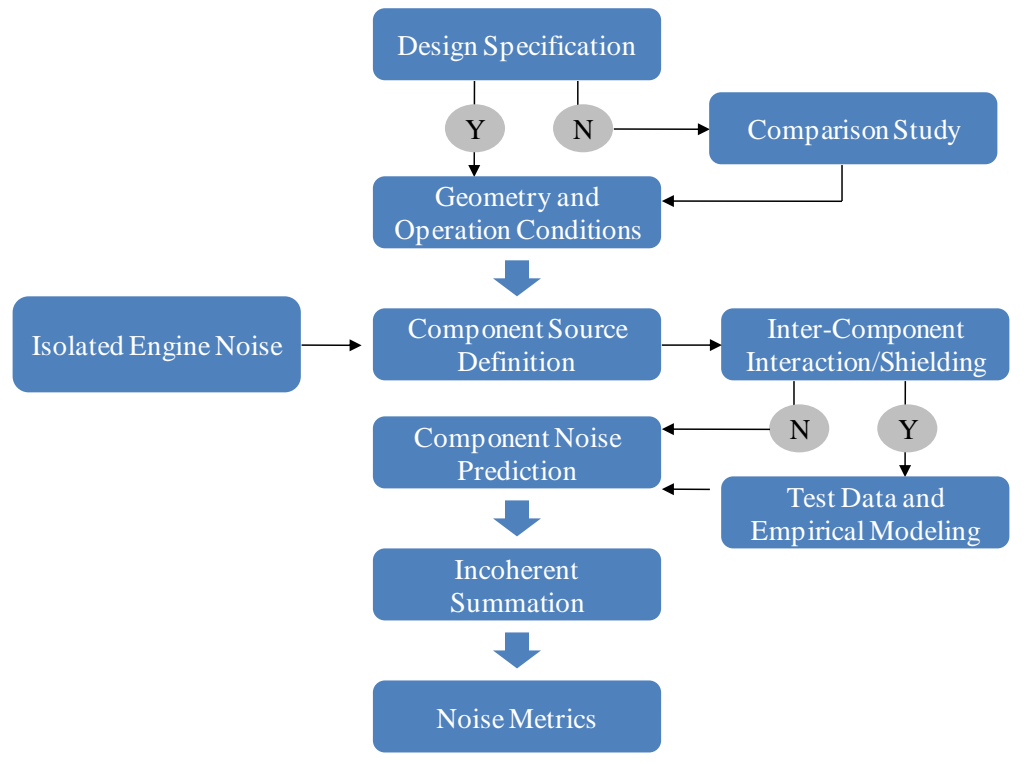

Figure 4. Illustration of acoustic analysis process.

In the acoustic analysis procedure described above, the predictions of the airframe noise components, namely, the leading edge slats, the landing gears and the trailing edge elevons, are based on methodologies developed for airframe noise components of conventional aircraft (Ref 21 - 24). These prediction models can be applied here for the BWB design because the basic elements of the prediction methodologies, such as the spectral features, the Mach number dependence, and the far field directivity of the radiated noise, are based on the fundamental theory of aerodynamic sound generation (Ref 11) that captures the flow physics. The predictions are all component-based, with the noise prediction as a function of the local features of the individual components, rather than the overall design of the aircraft. The validation and calibration of the prediction models are also done for the individual components, and are not anchored on any particular aircraft type. This allows the models to have wide and robust applications. The BWB aircraft configuration, however, does have features different from conventional designs, an example being the large angle of attack at both takeoff and landing configurations, typically above 10 degrees, which is not within the operational range of conventional aircraft, of about 4 to 8 degrees. Thus, slat noise database for conventional aircraft usually does not extend to angles of attack much higher than 8 degrees, and the prediction of BWB slat noise needs to be validated and calibrated for large angles of attack. This is done by using the database reported in Ref 25, where a model scale BWB was tested in the Boeing Low Speed Aeroacoustics Facility (LSAF) with variations in the aircraft angle of attack covering the entire range of operation, from zero to 15 degrees. The original prediction model is then extended to cover all the angles of attack for the slat noise. 
Another feature of the BWB design that is different from conventional aircraft is the locations of the main landing gears, which affect the noise because the local geometry determines the local flow velocity that in turn sets the flow-dependent part of the noise amplitude. For conventional aircraft, the main landing gears are located in low speed flows under the lifting wings so that the locations are acoustically advantageous (Ref 26, 27). In comparison, the BWB main landing gears are in relatively high speed flows without taking advantage of the circulatory flow around the wings, because they are located at the junctions between the BWB center body and its outer wings where the flows accelerate. For landing gear noise prediction, the sound generation mechanisms are all modeled with the incoming flow velocity as an input parameter. Thus, the landing gear noise model is readily applicable, provided that the local flow velocity is supplied. This is done by using Computational Fluid Dynamics (CFD) method to calculate the mean flow for the BWB aircraft configuration, from which the local flow velocities are extracted for the landing gear noise prediction.

The prediction of engine noise is another critical element in the acoustic analysis methodology. In addition to the prediction of the noise source levels of the open rotor engines, the effects of the BWB airframe on the engine noise, namely, the shielding effects, must be accurately and realistically accounted for because the engine noise reduction due to the BWB shielding is the main factor that may potentially make the BWB with open rotor propulsion acoustically viable as a candidate for future commercial aircraft. The engine noise source levels, including the tones and the broadband components, are predicted by empirical methods, calibrated by the data reported in Ref 10 . Due to the lack of full scale open rotor noise tests and database, especially for more advanced designs developed in recent years, the predictions can only be calibrated with limited small scale wind tunnel test data. The projection of the predictions to full scale, however, has shown good consistency with other independent methods and database (Ref 4), which all indicate that the more recent designs of open rotor engines may meet the aircraft noise regulation of Stage 4 with about 13 cumulative EPNL dB margin.

The effects of the BWB shielding on the open rotor noise are obtained from a database resulting from a model scale wind tunnel experiment in the Boeing LSAF reported in Ref 28. The method for extracting and applying the shielding effects in this system noise assessment is described in Ref 29. The test setup is illustrated in Figure 5, showing the LSAF test section, the BWB airframe model and the open rotor rig. There is a huge database covering parametric variations in flow conditions, BWB airframe design features, engine power settings, rotor operational conditions, engine-airframe integration configurations, and noise reduction concepts, with measurements on the aircraft, in the near field flow, and in the far field. The processing and analysis of the database is beyond the scope of the work discussed here, but some aspects should be discussed, which are related to the system noise prediction and may have significant impact on the assessment methodology and results.

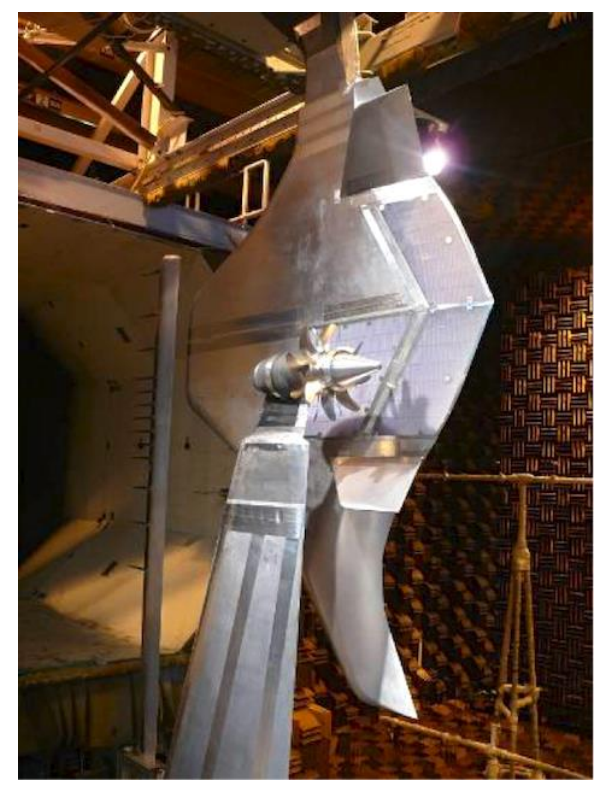

Figure 5. Test setup for the BWB model with open rotors installed in the test section of LSAF (from Ref 28).

Due to the tonal nature of the open rotor noise, the application of the noise shielding effects from a wind tunnel test to full scale engines needs to be on the individual tones, which is different from the case of turbofan engines 
dominated by broadband jet noise, where the noise shielding is usually applied on the $1 / 3$ octave band spectra, once the power settings are matched between the full scale engines and the scaled-up wind tunnel test engines. This is because turbofan engines dominated by jet noise follow similar acoustic behavior that is in turn mostly dominated by the engine power settings. On the other hand, the acoustic characteristics of open rotor engines, their tonal frequencies, the tone amplitude distributions, and the directivities of the tones, are critically determined by the detailed designs and operating conditions of the open rotors. Thus, there is no guarantee for matching acoustic characteristics between two different designs, even if they can be operated to have the same power outputs. Of course, if the engines in the wind tunnel test have the same design as the full scale engine, the acoustic features of the two would be scalable and the shielding effects can be applied on the 1/3 octave band spectra. This is, however, not likely to be the case in practical situations, especially when the technologies of open rotor design are still in development. Instead, costly wind tunnel tests may be done using a generic rotor design and the results should be suitably processed and applied to various full configuration designs. In this approach, the open rotors in the wind tunnel test serve, among other reasons, as realistic tone generators to gather shielding data at the individual tone frequencies. The shielding effects on the individual tones are relevant to other engines as long as the directivities of the tones individually match those of the tones in the full scale engines, even if the overall acoustic characteristics of the two are different, as analyzed in detail in Ref 29.

When applying wind tunnel test data to full scale configurations in flight, emission angle is one of the parameters that need to be corrected. This is well known, but is worth emphasizing for the BWB shielding study, because noise reduction due to shielding is highly directional, depending on the engine-airframe configuration. For engine noise that varies gradually in emission angles, the emission angle correction may not have a significant impact on the total noise, or the EPNL, because the correction essentially corresponds to an angle shift, and the total noise is the aggregate of the gradually varying noise from all angles. For the BWB configuration, however, the variations of the engine noise amplitudes with emission angles can be drastic, due to the shielding effects. For example, from the insonified angles to the shadow angles, a few degrees of emission angle can lead to a difference of 10 or $20 \mathrm{~dB}$ in noise amplitude. Furthermore, the most significant variations in noise amplitude often occur around the overhead direction which is heavily weighted in the calculation of the noise metric EPNL, because of the smaller propagation distance compared with other angles. Since the engines are located near the trailing edge of the BWB airframe, there is an angular domain in the aft quadrant of the flight that does not benefit from the shielding, namely, the insonified region. In the wind tunnel test, the flow increases the emission angles so that the emission angle correction will bring this insonified angular domain forward in the flight direction, leading to less shielding than what the wind tunnel data seem to show.

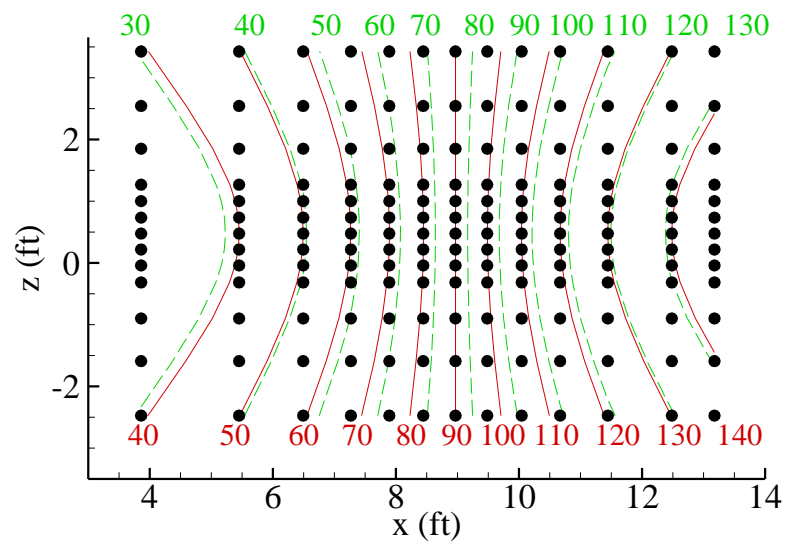

Figure 6. Illustration of emission angle correction for the microphones in the LSAF test.

To demonstrate the correction of emission angles, Figure 6 shows the inflow traverse microphone locations in the LSAF test by the black dots, the geometric angle curves from 40 to 140 degrees by the solid red curves with the values of the geometric angles indicated by the row of red numbers in the lower part of the plot, and the emission angle curves from 30 to 130 degrees by the green dashed curves with the values indicated by the row of green numbers at the top of the plot. The emission angles are calculated for the case of Mach number 0.24. By comparing the two sets of curves and their corresponding numbers, it is clear that the emission angle corrections are more than 10 degrees. For example, the column of dots at $x=9$ feet is the microphone locations at overhead on polar geometric angles, meaning that the engine center is aligned with these microphones in the $x$ direction with corresponding 
geometric angle of 90 degrees, as can be seen by the overlap of the dots and the straight red line marked by the number 90 . These overhead locations, however, are bracketed by the two green dash curves respectively marked by the green numbers of 70 and 80 , indicating that the emission angles of this column of microphones are between 70 to 80 degrees, more than 10 degrees lower than their respective geometric angles.

\section{Engine Noise Shielding}

As discussed in Ref 29, the BWB shielding effects should be applied to the engine source levels on the basis of individual tones, when the shielding effects are derived from tests with engine models of different scales and different rotor designs, which is most likely to be the case in practical applications, since open rotor engines are still in development and there is no production type. For the case studied here, the shielding effects are derived from a scale model test in the Boeing LSAF wind tunnel. The matching between the full scale BWB aircraft and the LSAF scaled model is illustrated in Table 3, where various geometric and fan design parameters are listed for both configurations. The first parameter listed in Table 3 is the fan diameters, the ratio of which gives the scaling factor of 0.066 that is used to scale the frequencies so that the Strouhal numbers are matched between the two cases. The next two parameters are the fan blade counts, which determine the tonal frequencies of the rotors. While the aft fan blade numbers for the two cases are close, the forward fans differ significantly. Preferably, the blade counts of the two cases should be equal so that the Blade Passing Frequency (BPF) and its high order harmonics would be scaled by the fan speeds. Since this is not the case here, the tonal frequencies are scaled by the Strouhal number, and the shielding effects are applied to the tones regardless of their origin and engine order.

Table 3. Parameters between the full scale BWB aircraft and the LSAF model.

\begin{tabular}{l|cc}
\hline & Full Scale BWB & LSAF Model \\
\hline Fan Diameter (in) & 182 & 12 \\
Forward Fan Blade Count & 12 & 8 \\
Aft Fan Blade Count & 9 & 8 \\
Engine Distance to BWB TE & $0.94 D$ & $1 D$ \\
Clearance, Rotor Tip to Airframe & $0.2 D$ & $0.25 D$ \\
Vertical Tail Height & $1 D$ & $1 D$ \\
Vertical Tail Angle (Deg.) & 45 & 30 \\
\hline
\end{tabular}

The next two parameters in the table are the distance from the engine center to the BWB airframe trailing edge and that to its upper surface, respectively. These two parameters are critical in determining the efficiency of the shielding, because together with the fan diameters, they determine the shielding, transitional and insonified regions, as illustrated in Figure 7. Once the frequencies are scaled by the Strouhal number, these two geometric parameters should be scaled in terms of the fan diameter. As shown in Table 3, the two parameters are matched well between the full scale BWB aircraft and the LSAF test setup. For engine locations that are not in the wind tunnel test database, a comprehensive data analysis and empirical modeling should be able to make the data useable, by interpolation, for example. In the study presented here, Table 3 shows that the engine location of the BWB design matches one of the scale model test configuration so that interpolation is not needed.

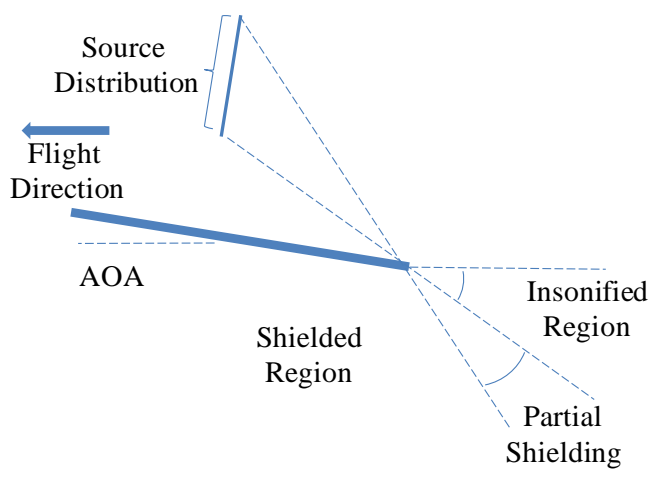

Figure 7. Definition and acoustic features of shielding angles. 
The last two parameters in the table are for the vertical tails, which will be discussed in a later section as a potential noise reduction device. The comparisons are given here for convenience. For both the full configuration and the model scale test, the heights of the vertical tail are about one fan diameter, giving a close match between the two. The vertical cant angles, however, are different between the two; the vertical tails of the full configuration are canted 15 degrees more outward from the engines. While it is believed that large cant angles are more efficient in reflecting the noise upwards, the impact of the angle difference between 45 and 30 degrees has not been quantified, and will need to be studied in the future. For the work reported here, this difference will simply be accepted with the understanding of the uncertainty and potential impact.

Once the full configuration design is matched with a wind tunnel test configuration, the data from the wind tunnel tests are extracted to derive the shielding effects, respectively for the three operation conditions. This is done by scaling the model scale test engine power to full configuration and matching the individual conditions. At each operating condition, the shielding effects are further decomposed into tones from the front rotor, the rear rotor, and the interactions of the two. This decomposition is necessary because each group of tones have its own distinctive radiation patterns and far field directivity, which can significantly affect the shielding results. Some examples are illustrated in Figure 8, which plots the noise reduction due to shielding for the tones of the full scale engine, located off the centerline of the BWB airframe for the baseline configuration. The two diagrams are respectively for the overhead and the sideline direction. The figure plots the difference in SPL between isolated and installed engines as a function of the emission angle and frequency. For the engine located on the BWB airframe centerline, the results are similar but quantitatively different.
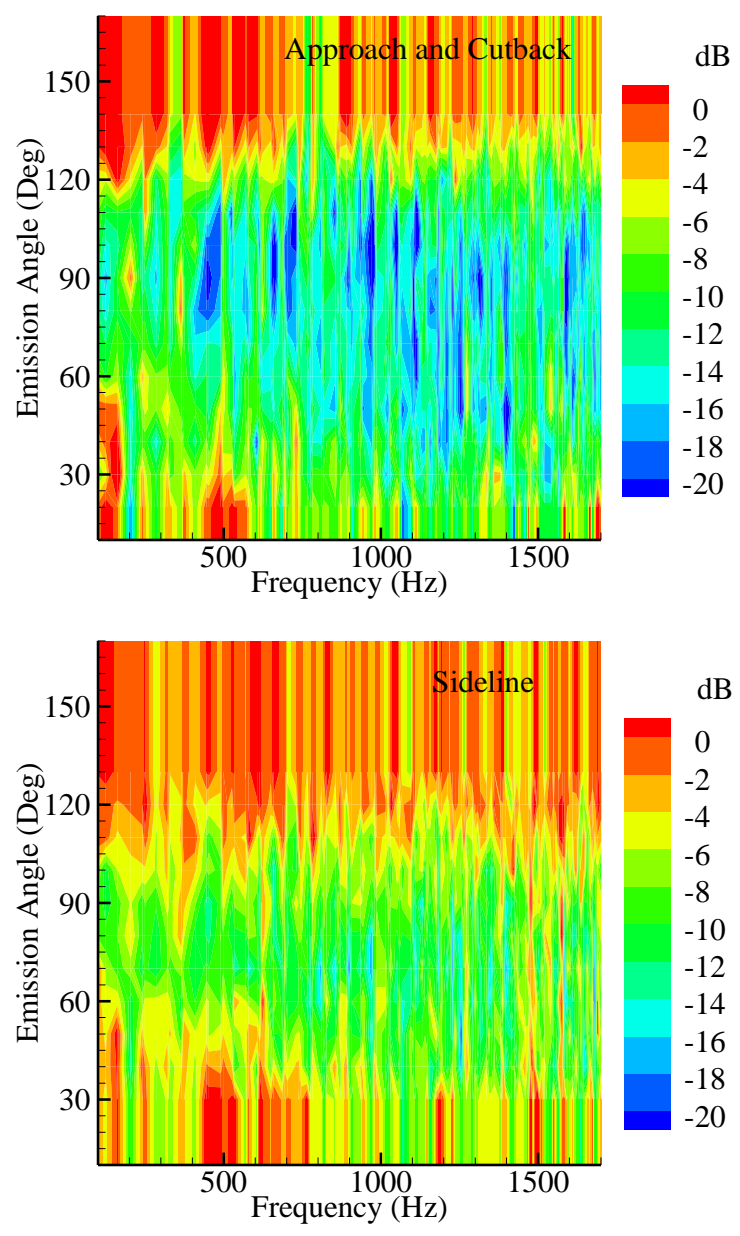

Figure 8. Tonal noise shielding for engines located off the BWB center for the baseline configuration.

From the results shown in Figure 8, some representative trends can be derived. For both the overhead and the sideline direction, the effectiveness of noise shielding increases with frequency, indicated by the widening of the green/blue area with frequency. This is the well-known feature of better shielding of shorter sound waves due to 
higher frequency for fixed source position. The heavily shielded area with the green/blue colors is mostly in the forward quadrant, because of the engine location near the trailing edge of the BWB airframe, which also leads to the result of basically no shielding at large emission angles in the aft quadrant, namely, the red colored region after about 120 degrees for the overhead case and after about 105 degrees for the sideline case. This also states that the overhead direction sees more shielding than the sideline direction, a feature readily explainable by the shape of the BWB airframe. The engines are located near the airframe centerline where the chord length is largest, which causes a large angular domain with blocked sound propagation if the propagation is downwards, namely, in the overhead direction. The waves propagating in the sideline direction, however, encounter a shielding surface with smaller chord length because of the tapering of the wing design. Furthermore, the trailing edge of the BWB is not an unswept straight line. Instead, it curves in the upstream direction along the span, as can be seen from the photo in Figure 5, which leads to an unblocked area for the sound waves to propagate to the sideline without interference with the airframe and is the reason for the forward shift of the shielding angle in the results shown in the two diagrams in Figure 8.

When using the wind tunnel test data to extract the shielding effects of the tones, the remaining spectra after the tone extraction also gives the shielding effects for the broadband noise of the rotor engines, which are scaled to full scale by the engine size ratio and then applied to the full scale configuration for $1 / 3$ octave bands from $50 \mathrm{~Hz}$ to $10000 \mathrm{~Hz}$. Examples of the broadband shielding effects are shown in Figure 9, with the difference in the 1/3 octave band SPL plotted as a function of the emission angle and the logarithmic of frequency for engines located off the BWB centerline. Clearly, the amount of broadband shielding is different from tonal shielding, but the functional trends in frequency and emission angle hold for both tonal and broadband shielding, as evidenced by the similar features revealed in Figure 8 and Figure 9.
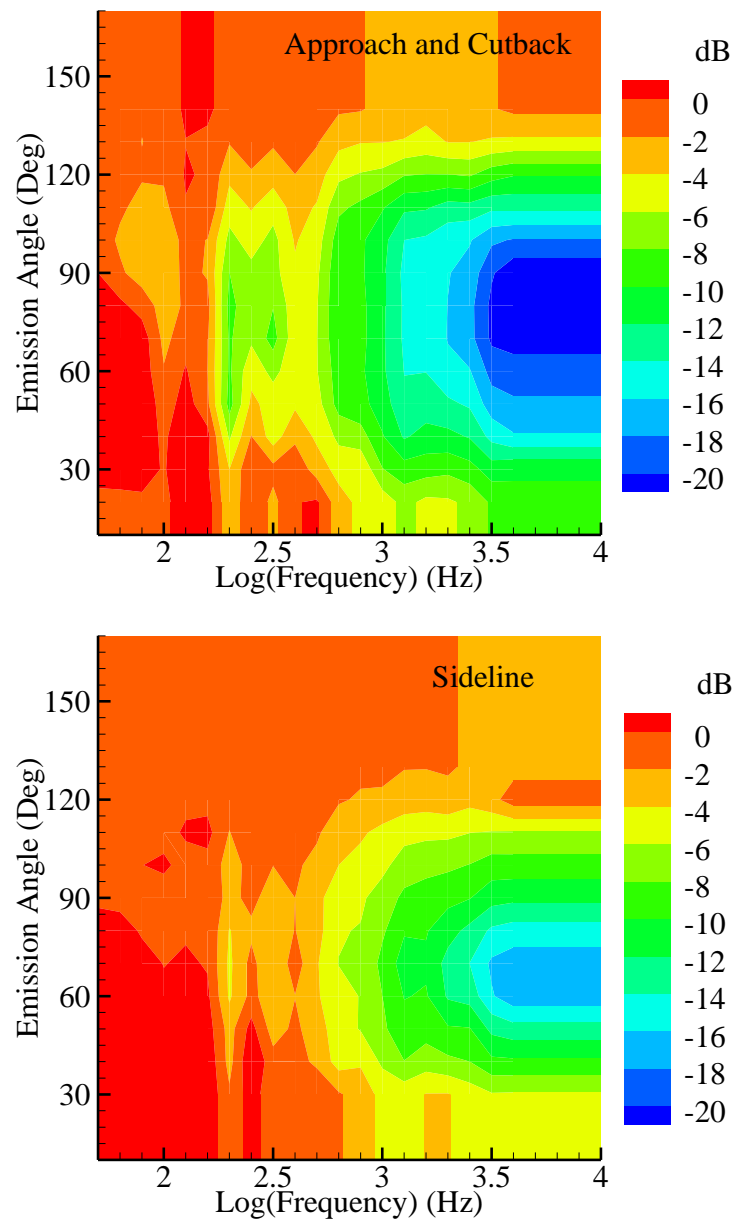

Figure 9. Broadband shielding for engines located off the BWB centerline for the baseline configuration. 


\section{System Noise of Baseline Configuration}

The system noise study starts with the baseline configurations with both the propulsion systems and the airframe configurations as designed, details of which are described in Ref 10 . The designs follow some general principles to minimize noise, but there is no acoustic optimization and parametric studies. Instead, all the configurations are designed to meet aerodynamic and propulsion requirements. Thus, the acoustic analysis serves only as assessments of these as-designed configurations. An example is the locations of the engines above the airframe. This engineairframe configuration reduces the total aircraft noise by shielding and the locations of the engines in relation to the airframe trailing edges play a critical role in the shielding efficiency. The configuration studied here has not been optimized for maximum shielding effects. Instead, the engine locations are determined by other requirements such as the aerodynamic-propulsion integration, aircraft weight balance and stability control, and engine operability. The noise analysis is based on these designs, implying the potential of further noise reduction with optimization studies within the requirements of other design criteria. This is also the case for noise reduction technologies; the baseline designs do not include various noise reduction concepts that are currently in development. An example is landing gear fairings, which, while still facing significant hurdles in practical implementations, have been demonstrated to have noise reduction potential (Ref 18-20). The fairings can be implemented in various forms, from small local fairings to cover some particular gear parts to overall fairings to completely shield the gear from the incoming flows. These come with varying degrees of difficulty in practical implementation and will of course result in varying degrees of success in noise reduction. The baseline BWB design considered here takes some credit for gear noise reduction, corresponding to local fairings.

One reason for focusing first on the acoustic assessment of the baseline configuration is to highlight the design that is considered to be most practically feasible within the 2025 timeframe. Another reason for the baseline acoustic analysis is to demonstrate the multiple paths to achieve further noise reduction goals. With the baseline configuration as the starting point, further noise reduction can be projected from various combinations of approaches ranging from configuration optimization, to component noise reduction, to low noise operation procedures. The selection of the combination will most likely depend on other practical constraints in the aircraft design and the maturity of the individual technologies. It also illustrates the necessity of this multi-path approach in achieving noise reduction goals such as the NASA N+2 noise goal; an individual technology, even if optimized, may not be able to achieve such a goal, due to the system nature of the aircraft design. The engine noise shielding by the BWB airframe, again, offers a good example. The baseline BWB configuration analyzed here provide good shielding, and though further noise reduction can be expected with optimization of the engine locations, this additional reduction can be expected to have limited effects on the total noise reduction, and hence, may not be enough to reach the NASA N+2 noise goal, because airframe noise will be a major contributor to the total noise. Thus, technologies other than engine noise shielding will be necessary and critical, and these technologies need to be prioritized and developed from the point of view of aircraft systems, not isolated concepts.

With the methodologies and data described in the previous sections, the noise metrics for the baseline configuration are calculated and summarized in Table 4, which lists the limits of the noise regulation of Stage 3 at the three certification conditions and their cumulative value as the first row of data in the table. The EPNL for the BWB aircraft is then given in the second row, which leads to the margins given in the next two rows respectively in reference to the regulation limits of Stage 3 and Stage 4, the latter being the current regulation for aircraft certification. Clearly, this is a quiet aircraft, with about $24 \mathrm{~dB}$ cumulative EPNL margin to Stage 4. As a reference comparison, the latest generation of commercial aircraft currently in service, the Boeing 787, for example, which has the conventional design with turbofan engines and has comparable takeoff weight to the BWB configuration studied here, has cumulative EPNL about $16 \mathrm{~dB}$ below Stage 4. The low noise levels of the BWB design become even more impressive when considering the BWB design uses open rotor engines; for the latest advanced rotor designs installed on a conventional tail mounted tube-and-wing aircraft, Ref 4 has reported a cumulative EPNL margin of about $13 \mathrm{~dB}$, much less than the $24 \mathrm{~dB}$ for the BWB design.

Table 4. Acoustic results for the baseline configuration.

\begin{tabular}{l|cccc}
\hline & Approach & Cutback & Sideline & CUM \\
\hline Stage 3 EPNL Limits (dB) & 103.7 & 99.9 & 100.3 & 303.9 \\
EPNL (dB) & 94.5 & 86.2 & 89.2 & 269.9 \\
Margin to Stage 3 (dB) & 9.2 & 13.7 & 11.0 & 34.0 \\
Margin to Stage 4 (dB) & - & - & - & 24.0 \\
\hline
\end{tabular}


The low noise levels of the BWB aircraft are achieved mostly by the shielding of engine noise by the BWB airframe structure. This can be demonstrated by a reference comparison between the BWB design and a hypothetical aircraft that uses the same open rotor engines, but does not provide any engine noise shielding. To be relevant, the hypothetical aircraft is assumed to have the same levels of airframe noise components as the BWB aircraft. It is also assumed to operate with the same flight profiles. The noise levels of this hypothetical aircraft are compared with the BWB aircraft in Table 5, showing the significant benefit of the BWB noise shielding. The shielding benefits all three certification conditions with noise reduction of 2.5, 3.8 and $4.3 \mathrm{~dB}$, respectively for the approach, the cutback and the sideline condition. It should be pointed out that this hypothetical aircraft is used here only for the purpose of demonstrate the effects of noise shielding by the BWB airframe. It is by no means an indication of the noise levels for conventional aircraft designs with open rotor engines, which have drastically different airframes, and thus, very different airframe noise levels. Because of the differences in airframe design, conventional aircraft also operates with flight profiles different from those of the BWB aircraft, such as the flight Mach number and aircraft angle of attack. Furthermore, for engines installed under the wings of conventional aircraft designs, the installation effects can also have significant effects on the total aircraft noise.

Table 5. Comparison between BWB and a hypothetical aircraft without noise shielding.

\begin{tabular}{l|cccc}
\hline & Approach & Cutback & Sideline & CUM \\
\hline Stage 3 EPNL Limits $(\mathrm{dB})$ & 103.7 & 99.9 & 100.3 & 303.9 \\
BWB EPNL (dB) & 94.5 & 86.2 & 89.2 & 269.9 \\
Hypothetical Aircraft EPNL (dB) & 97.0 & 90.0 & 93.5 & 280.5 \\
Shielding Effect $(\Delta \mathrm{dB})$ & 2.5 & 3.8 & 4.3 & 10.6 \\
\hline
\end{tabular}

From Table 5, it can be seen that though the BWB shielding is largely responsible for the comfortable EPNL margin of the baseline configuration, the advanced rotor design itself also has good acoustic characteristics. Even without the BWB shielding, the hypothetic aircraft would still meet the regulatory noise requirements, with a noise margin of EPNL about $13.4 \mathrm{~dB}$, very consistent with the result reported in Ref 4 . The combination of advanced rotor design and BWB shielding is so efficient in reducing the engine noise at approach conditions that the engine noise is no longer the dominant component. This can be seen from the component decomposition shown in the top diagram of Figure 10, which plots the tone corrected perceived noise level (PNLT) as a function of the observer time for both the airframe and the engine noise component, as well as the total. In this case, the engine noise, indicated by the green dashed line, still has noticeable contributions in the aft quadrant, namely, at large observer times after the peak noise point in the diagram, but the dominant component elsewhere is the airframe, shown by the red curve in the figure. The other two diagrams, the middle and the bottom one, in Figure 10 plot the noise decomposition in PNLT respectively for the cutback and the sideline conditions. It can be seen that for all three conditions, the engine noise components are significantly reduced in the forward quadrant, namely, at observer times before the peak noise time in the figure when the observer is ahead of the aircraft. The engine noise levels are much lower on the left side of the peak noise points, compared with the levels on the right side. This is expected because the engines are located close to the trailing edges of the BWB airframe so that most shielding occurs in the forward directions. The figure also shows that the engine noise from the open rotors, though benefitting from the BWB shielding, is still a dominant contributor to the total aircraft noise, especially in the aft quadrant where shielding is limited. This is true for all three conditions, but especially at sideline and cutback.

For the approach conditions when the airframe is the major contributor to the aircraft total noise, the noise decomposition can be carried out further for all the airframe noise components, as shown in Figure 11, where the main landing gear is seen to be the dominant component. This relatively high noise level is the result of high local velocities at the main landing gear location. As designed, the main gears are positioned at the junction between the BWB center body and its outer wings, where the sectional lift is very small, corresponding to small circulation at this span-wise location, which in turn makes the flow velocity under the airframe close to the free stream velocity. In comparison with conventional aircraft with the main landing gears located under wing sections with large sectional lift, the local flow velocity under the wing is usually reduced by as much as 20 percent by the circulatory flow that is in the opposite direction as the free stream. Since the landing gear noise is proportional to the $6^{\text {th }}$ power law in the flow Mach number, a 20-percent reduction in flow velocity corresponds to about $6 \mathrm{~dB}$ noise reduction. The BWB design does not take advantage of this velocity reduction, and thus suffers from relatively high landing gear noise. 

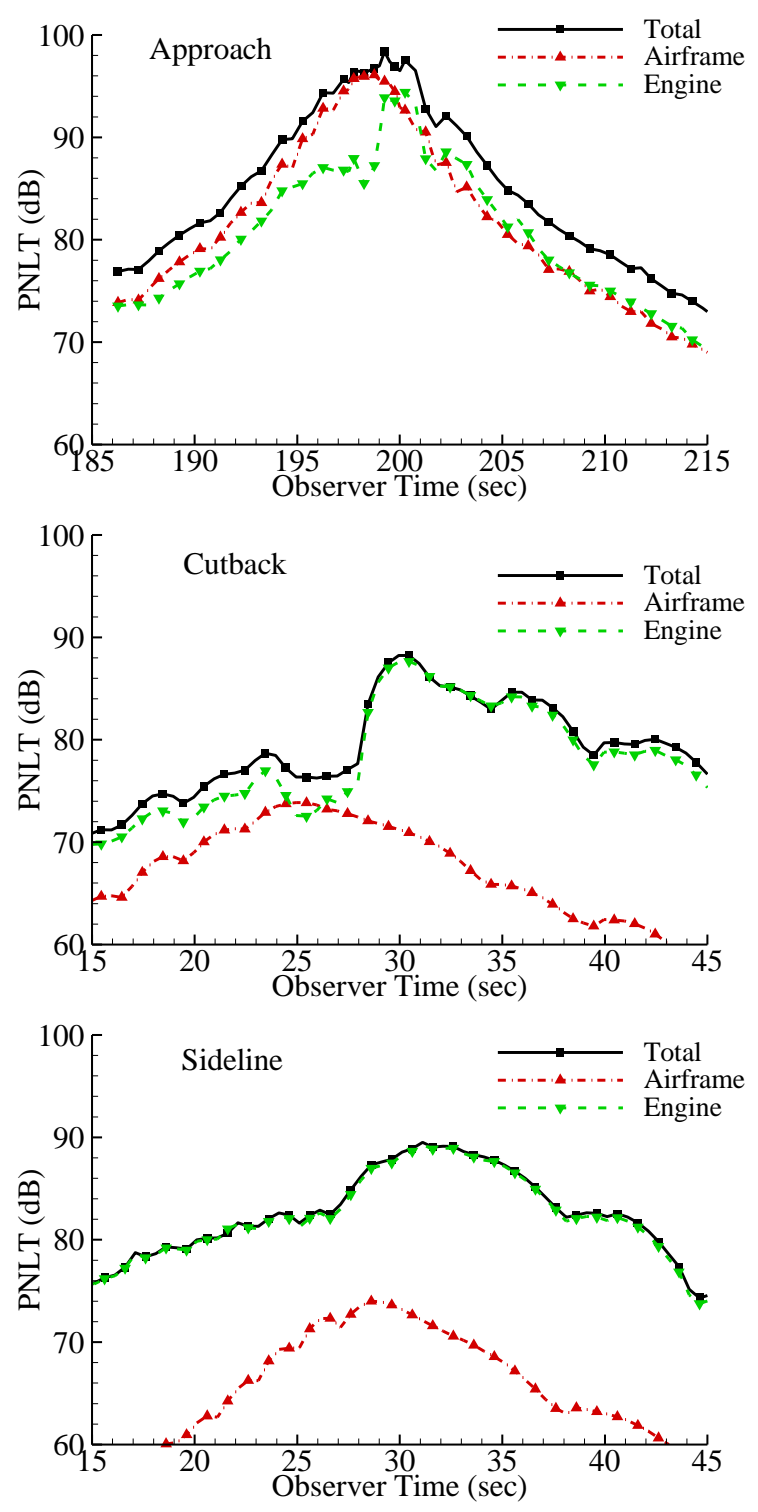

Figure 10. PNLT for the baseline configuration at the three noise certification conditions.

The dominance of the main gear noise is in part a function of the relatively low amplitudes of the other airframe components, especially the slat noise component that is usually somewhat comparable to landing gear noise for conventional aircraft. The relatively low slat noise results from the use of Krueger slats, minimizing large scale cove region flow separation, and thus, reducing its noise. The effect is equivalent to the slat noise reduction technique of a cove filler. The slat noise is also low because sealed slats are assumed for the BWB design, which may be implemented in the form of hinged Krueger slats. The elimination of the slat gap significantly reduces the slat noise, which has been experimentally demonstrated in the past (e.g. Ref 13, 14). It is interesting to point out that the BWB slat noise would be much higher, probably comparable to or higher than that of a conventional aircraft design of comparable size, had the design used conventional slotted slats, as analyzed in Ref 25 . The hinged Krueger slats used here were originally designed to protect laminar flow control devices, but they could turn out to be of some acoustic advantage as well. It should also be pointed out that for both conventional slotted slats and Krueger slats, the noise modeling and prediction are for the slats themselves without considering the effects of the slat brackets. Currently, the noise from the slats themselves is considered to be much higher than that from the supporting brackets, so that the bracket noise is ignored, similarly assumed for other airframe noise components. For Krueger slats, the number of brackets and the complexity of the brackets may be very different from those for conventional slotted slats, which would then represent a new noise component. This has not been studied so far because Krueger 
slats have not been widely used in the current generation of commercial aircraft and there is no data available for even an order of magnitude assessment, a situation that certainly needs to be rectified if Krueger slats become the choice of future aircraft design.

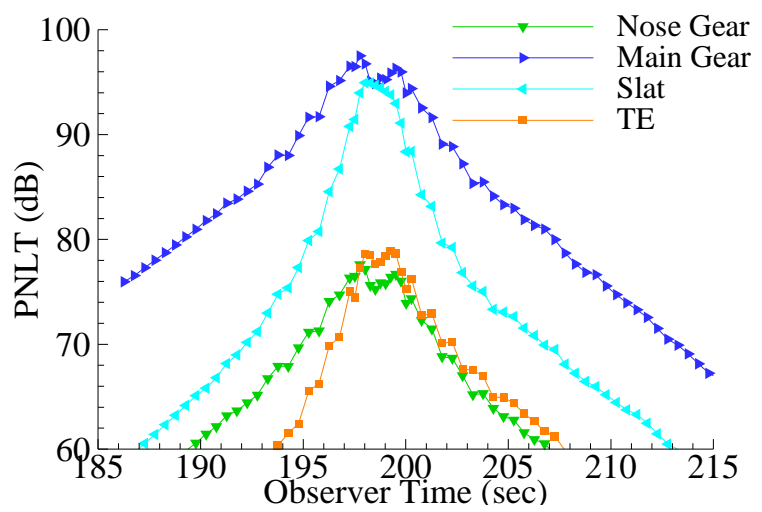

Figure 11. PNLT for airframe components for the baseline BWB design.

From the results discussed above, it is clear that the noise levels of the open rotor powered BWB aircraft benefit significantly from the noise reduction provided by the noise shielding of the BWB airframe, which gives the aircraft a comfortable EPNL margin of about $24 \mathrm{~dB}$ relative to Stage 4. Even with the potential of a more stringent regulation of Stage 5 in the next decade or so, this would still be sufficient to meet the regulatory requirements. Thus, purely from the acoustics point of a view, the BWB aircraft with open rotor propulsion would be a viable candidate as a commercial aircraft. This, however, does not necessarily imply the commercial competiveness of such aircraft design. In fact, it is likely to meet stiff competitions from turbofan powered aircraft, either conventional or BWB design, because of their acoustic advantages. For example, the latest generations of conventional aircraft in service already have cumulative EPNL margins to Stage 4 in the range of 16 to $20 \mathrm{~dB}$, which is not as much as the $24 \mathrm{~dB}$ margin for the BWB aircraft, but the noise levels of the conventional aircraft are achieved with current designs and technologies, while the BWB aircraft is projected to mature in a decade or so. There is no doubt that conventional aircraft design will also advance in the timeframe and new technologies will make its noise levels lower. This will definitely put competitive pressure on the BWB aircraft; a noise advantage of about $4 \mathrm{~dB}$ in cumulative EPNL for a future design can be definitely considered as a competitive risk.

It is also obvious that the noise levels do not meet the NASA N+2 noise goal of $42 \mathrm{~dB}$ below Stage 4 . There are various reasons for this relative status including the high source noise levels of the open rotor engines compared with turbofan engines, the limited shielding efficiency of low frequency tones with the engines mounted close to the BWB trailing edges, and the high airframe noise components of the BWB design. These reasons also point to directions to improve the design and further reduce the noise levels, which will be discussed in the following sections.

\section{Effects of Engine Locations}

The most influential parameter for the efficiency of BWB engine noise shielding is probably the engine locations. It is also known that the engine locations are constrained by factors such as aerodynamic-propulsion integration, aircraft weight balance and stability control. The baseline design discussed in previous sections with the engines installed approximately 1D upstream of the trailing edges of the BWB airframe is probably pushing the design envelope; this location is approaching the edges of the high speed flow zone on the upper side of the aircraft. This is a situation to be avoided in aircraft design because the intrusion of the engines into the high speed flows would not only destroy the flow pattern, severely degrading the aerodynamic performance of the design, but also expose the engine to the high speed inflow, decreasing the engine propulsion efficiency. It is believed that to ensure feasible aerodynamic propulsion integration, the engines may have to be located within $0.75 \mathrm{D}$ of the trailing edge. It should be realized that this is the design status with current and near-term technologies of aero-propulsion integration; future development of advanced integration technologies may be able to extend this design envelope to allow engine/airframe integrations with better acoustic benefits. For this reason, it is instructive to assess the effects of engine location on the total aircraft noise. This quantitative trend between the total noise and the engine location can be used to perform trade studies to achieve a best balance between noise and other design parameters. 
Table 6. EPNL (dB) for various engine locations in the flow direction.

\begin{tabular}{c|ccccc}
\hline $\begin{array}{c}\text { Engine Position } \\
\text { From Trailing Edge }\end{array}$ & Approach & Cutback & Sideline & Cumulative & $\begin{array}{c}\text { Margin to } \\
\text { Stage 4 }\end{array}$ \\
\hline$-0.5 D$ & 97.2 & 91.1 & 94.2 & 282.4 & 11.5 \\
$-0.25 D$ & 97.1 & 91.1 & 94.0 & 282.2 & 11.7 \\
$0 D$ & 96.3 & 90.3 & 93.8 & 280.3 & 13.6 \\
$0.25 D$ & 96.5 & 89.7 & 93.2 & 279.3 & 14.6 \\
$0.5 D$ & 95.2 & 87.9 & 91.8 & 274.9 & 19.0 \\
$0.75 D$ & 95.7 & 87.2 & 90.4 & 273.3 & 20.7 \\
$1 D$ & 94.5 & 86.2 & 89.2 & 269.9 & 24.0 \\
$1.5 D$ & 93.6 & 82.6 & 87.7 & 263.9 & 30.0 \\
$2 D$ & 93.2 & 79.2 & 85.9 & 258.3 & 35.6 \\
\hline
\end{tabular}

To this end, Table 6 shows the results of at various engine locations, measured by the rotor diameter, with zero indicating the engines being at the trailing edge, positive numbers for positions upstream of the trailing edge and negative numbers for positions downstream of the trailing edge. For all the cases in this table, the aircraft configurations and flight conditions are the same as those for the baseline configuration discussed in the previous section. The most obvious trend shown in this table is the increase in noise shielding as the engines move upstream of the trailing edge, as can be intuitively expected because of the increase in shielding surface area. The results also show that the variations in shielding effects are not linear. Instead, the amount of shielding varies very gradually when the engines are behind the trailing edge, but increases significantly as the engines move further upstream of the trailing edge, beyond one rotor diameter. The increase in shielding as a function of the engine positions is not uniform for all three certification conditions either. The increased shielding tends to benefit the cutback condition the most. These features are also illustrated in Figure 12 where the EPNL variations for the three certification conditions are plotted in the top diagram and the cumulative EPNL in the bottom diagram.
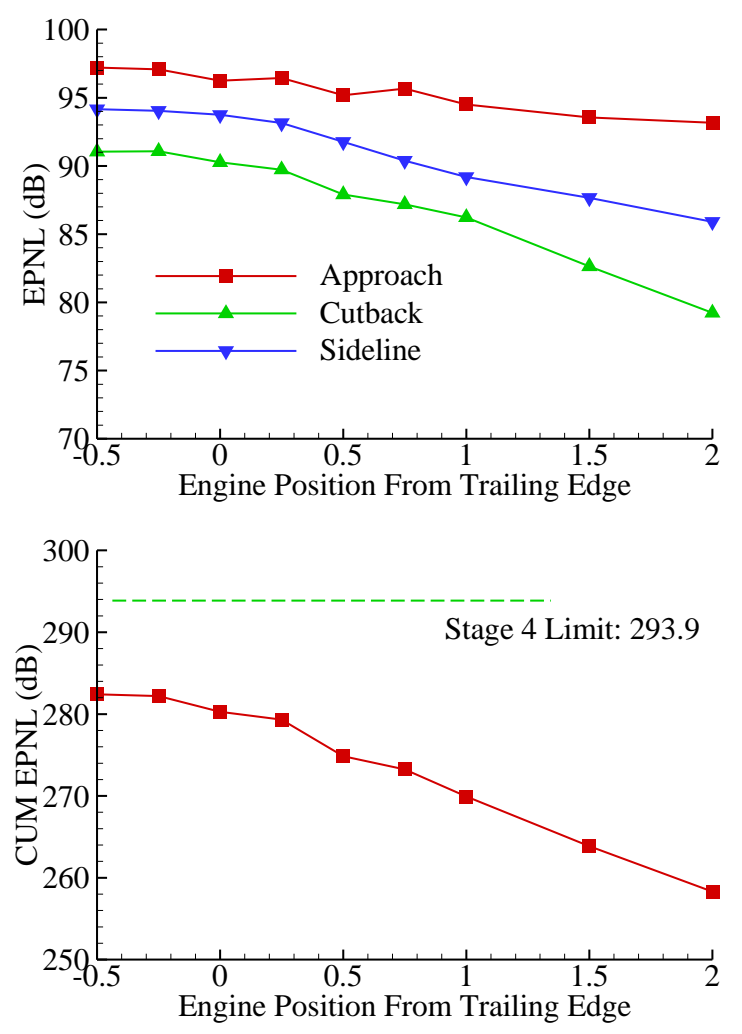

Figure 12. PNLT variations as a function of engine position in the flow direction. 
Though a BWB aircraft design with the engines located $2 D$ upstream of the trailing edge would have to overcome some significant technical hurdles to become a viable aircraft product, it is instructive for acoustics purposes to examine the noise decomposition for this configuration to reveal the effects of shielding and to identify the dominant noise sources. The PNLT components are shown in Figure 13 for this configuration, as a function of the observer time for the three noise certification conditions. Clearly, in comparison with the baseline case of engine locations $1 D$ upstream of the trailing edge, shown in Figure 10 and Figure 11 in the previous section, the engine noise from the open rotors is significantly reduced, as expected by the increased effective shielding surface area. The amounts of noise reduction for the three conditions, however, are not uniform, with more than $10 \mathrm{~dB}$ at the peak PNLT levels for the approach and cutback conditions, but only about half of that amount at the sideline conditions. This is also expected because the sideline angles are blocked by the airframe less than the overhead angles.
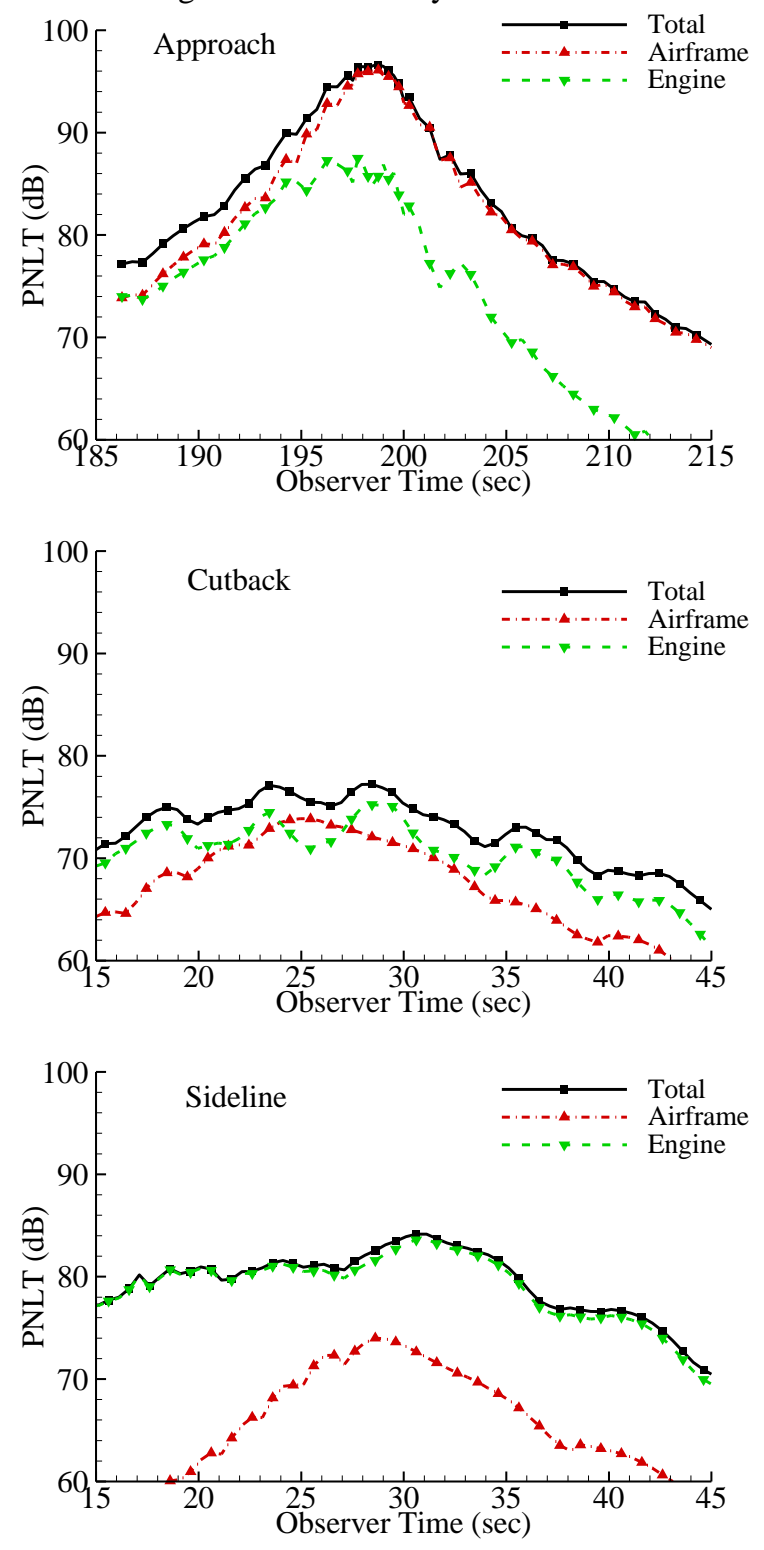

Figure 13. PNLT dB for the configuration with the engines at $2 D$ upstream of the BWB trailing edge.

It can be seen from the top and middle diagram in this figure that the engine noise reduction at the approach and cutback conditions are so significant that for the former the main landing gear noise is now the dominant component, given the ranking of airframe components in Figure 11, and for the latter the slat noise and the trailing edge noise components are now only slightly lower than the engine noise. On the other hand, the bottom diagram of this figure shows that the sideline noise is still dominantly from the rotors. From these observations, it can be 
suggested that the efficiency of engine noise shielding by the BWB airframe is probably approaching its maximum when the engines are located about $2 D$ upstream of the trailing edge; further reduction of the total aircraft noise would have to come from airframe noise reduction and/or engine noise source level reduction.

Engine locations can also vary in the direction normal to the airframe surface, within the range of practical constraints to avoid the boundary layer ingestion into the engine on the lower side and the issues of extra long supporting structure and stability control on the higher side of the range. This effect is shown by the results in Table 7 for the variations of aircraft EPNL as a function of the engine height from the BWB surface, respectively at the stream-wise position of $0.5 D$ and $1 D$ upstream of the trailing edge. The engine height in these tables is measured in rotor diameter from the engine axis line to the BWB upper surface, and the acoustic results given both in absolute levels and in the margins to Stage 4. In both cases, the variations are within a maximum of $1.7 \mathrm{~dB}$ for the individual conditions and about $1.5 \mathrm{~dB}$ for the cumulative levels. It can be noted that the variations in noise levels are not monotonic with the engine installation height, because the installation effects include both the shielding and the source level changes. The latter is due to possible potential field interaction, inflow distortion into the rotor, entrainment of the airframe boundary layer, and/or interaction with the rotor wake and BWB trailing edge, as the rotors are very close to the BWB surface. Obviously, the effects of shielding and source level changes compete with each other; the former increasingly lowers the far field noise by the increased shielding region as the rotors move closer to the airframe, as illustrated in Figure 7, while the latter causes more noise radiation with decreasing engine height because of the increased flow effects. Thus, an optimal engine installation height may exist at which the aggregate effects of all the features yield minimum far field noise. This can be seen from the limited datasets shown in Table 7. For example, the cumulative EPNL margins to Stage 4, shown in the last columns of the tables, seem to achieve maximum around the engine centerline height of about $0.83 \mathrm{D}$ and around $0.75 \mathrm{D}$ when the rotors are moved further downstream, where the boundary layer growth requires the engines further away from the BWB surface to avoid the flow interaction.

Table 7 EPNL (dB) for various engine heights.

\begin{tabular}{c|cccccc}
\hline $\begin{array}{c}\text { Engine } \\
\text { Location }\end{array}$ & $\begin{array}{c}\text { Engine Height } \\
\text { From BWB }\end{array}$ & Approach & Cutback & Sideline & Cumulative & $\begin{array}{c}\text { Margin to } \\
\text { Stage 4 }\end{array}$ \\
\hline \multirow{4}{*}{$0.5 D$} & $0.67 D$ & 95.6 & 87.9 & 92.8 & 276.3 & 17.6 \\
& $0.75 D$ & 95.2 & 87.9 & 91.8 & 274.9 & 19.0 \\
& $0.83 D$ & 95.4 & 87.4 & 92.6 & 275.4 & 18.5 \\
& $1 D$ & 95.3 & 87.6 & 93.1 & 276.0 & 17.9 \\
\hline \multirow{5}{*}{$1 D$} & $0.67 D$ & 95.1 & 86.9 & 88.3 & 270.3 & 23.6 \\
& $0.75 D$ & 94.5 & 86.2 & 89.2 & 269.9 & 24.0 \\
& $0.83 D$ & 93.4 & 85.9 & 89.4 & 268.7 & 25.2 \\
& $1 D$ & 93.5 & 86.0 & 89.7 & 269.1 & 24.8 \\
\hline
\end{tabular}

\section{Effects of Vertical Tails}

The use of vertical tails in BWB design is one of the unresolved issues; it is needed for stability control because of the lack of flaps in the BWB design, but this function may also be achieved by wing tips. Thus, the benefit of vertical tails to the overall design of aircraft performance is not conclusive. There have been studies showing that the added weight of the vertical tails may cost extra fuel by as much as three percent, which would be a strong reason for not having the vertical tails in the design, unless there are other significant benefits to offset the extra fuel cost disadvantage. One such benefit often quoted is the potential extra noise shielding at sideline conditions. The results in this section provide some quantification of this potential benefit.

The analysis starts with the baseline configuration discussed earlier, with the engines located one rotor diameter upstream of the trailing edge and three quarters of a rotor diameter above the BWB surface, and compares the baseline results with four additional configurations that involve the use of vertical tails. The four configurations consist of two sets of vertical tails respectively deployed at two cant angles. The two sets of vertical tails are named V1 and V3, where the former differs from the latter in its larger height, by approximately 50 percent. The two installation angles are respectively 102 and 120 degrees, with the straight vertical position defined as 90 degrees. An example is illustrated by the photos in Figure 14, which is the larger model deployed at 120 degrees. 


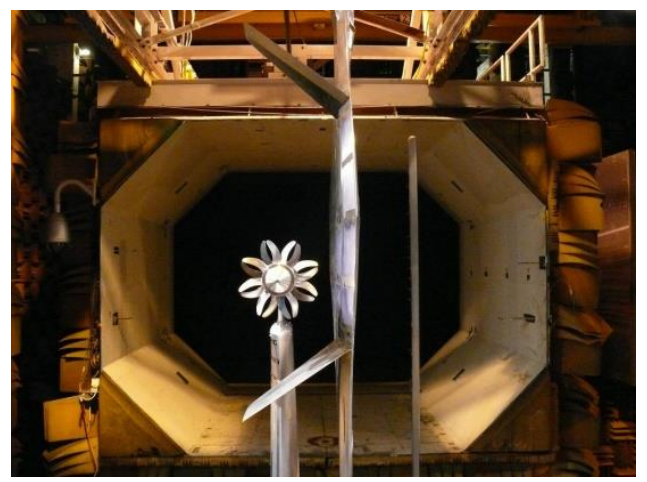

Figure 14. BWB configuration with vertical tails.

For the configurations with vertical tails, the results of EPNL are shown in Table 8, together with the results of the baseline configuration (no verticals), both for the absolute noise levels and for the margins to Stage 4 limits. Clearly, the vertical tails do not seem to provide a large benefit, with the V1 configuration providing noise reduction of less than one $\mathrm{dB}$ for the cumulative EPNL and the V3 configuration increasing the noise. This may seem surprising at first glance, considering the additional shielding surfaces provided by the vertical tails, but can be understood from the process of noise radiation and shielding from the open rotor sources to the far field microphones. For the sideline conditions, the far field measurement locations are not in two-dimensional geometry with the microphones receiving the noise radiated sideways from the source. The sideline emission angles are fully three-dimensional. Thus, while the vertical tails may block the 90-degree emission angle that is truly the sideway direction for the sideline certification conditions, the shielding effects in this direction are already significant due to the BWB baseline airframe. This is also the case for the angles in the forward quadrant where the shielding due to the large baseline airframe is already significant and the extra shielding surfaces due to the vertical tails are all enclosed in the shielding zone of the baseline airframe. For the angles in the aft quadrant that experience little shielding from the baseline airframe, since the vertical tails are located upstream of the trailing edge, they do not add any shielding surface for the angles in the aft quadrant, and thus, no significant acoustic benefits are expected.

Table 8. Effects of vertical tails on aircraft EPNL (dB).

\begin{tabular}{c|ccccc}
\hline $\begin{array}{c}\text { Vertical Tail } \\
\text { Configuration }\end{array}$ & Approach & Cutback & Sideline & Cumulative & $\begin{array}{c}\text { Margin to } \\
\text { Stage 4 }\end{array}$ \\
\hline V1 at $102^{\circ}$ & 94.2 & 86.6 & 88.3 & 269.1 & 24.8 \\
V3 at $102^{\circ}$ & 94.6 & 87.2 & 89.0 & 270.8 & 23.1 \\
V1 at $120^{\circ}$ & 94.3 & 86.8 & 88.3 & 269.3 & 24.6 \\
V3 at $120^{\circ}$ & 95.5 & 88.0 & 88.3 & 271.7 & 22.2 \\
Baseline & 94.5 & 86.2 & 89.2 & 269.9 & 24.0 \\
\hline
\end{tabular}

Table 9. $\Delta \mathrm{dB}$ of vertical tail effects from baseline configuration.

\begin{tabular}{c|cccc}
\hline $\begin{array}{c}\text { Vertical Tail } \\
\text { Configuration }\end{array}$ & Approach & Cutback & Sideline & Cumulative \\
\hline V1 at $102^{\circ}$ & -0.4 & 0.3 & -0.9 & -0.9 \\
V3 at $102^{\circ}$ & 0.1 & 1.0 & -0.2 & 0.8 \\
V1 at $120^{\circ}$ & -0.2 & 0.5 & -0.9 & -0.6 \\
V3 at $120^{\circ}$ & 1.0 & 1.7 & -0.9 & 1.8 \\
\hline
\end{tabular}

From the results in Table 8, the noise increments from the baseline configuration, due to the vertical tails, can be derived, which are shown in Table 9, for the four cases with vertical tails, at the three certification conditions as well as for the cumulative levels. In this table, positive numbers mean noise increase and negative number indicate noise reduction. For the cumulative levels, it is clear that the vertical tails have, at best, a noise reduction of less than $1 \mathrm{~dB}$ and the largest noise impact is actually an increase. The effects of the vertical tails can be further understood by the results shown in this table for the individual certification conditions. At sideline conditions, the effects are all noise 
reduction, which, though only by a small amount, is consistent for all four configurations. These effects, however, are largely offset by the noise increases in the other two conditions, namely, at approach and cutback. This is because the approach and cutback conditions are both for noise in the flyover path. The vertical tails obviously do not help the shielding along the flight path since they are located on the sides of the engines. Furthermore, the noise reflected back by the vertical tails from the sideway directions will propagate away in other directions, including the flyover directions, leading to the potential of increased noise along the flight path. This is similar to the effects of megaphones that enhance the sound in the directions which the megaphones are pointing at, as clearly seen by the results shown in the table; at approach and cutback conditions, the changes in noise levels due to the vertical tails are mostly noise increase. This noise increase of the megaphone effects is more prominent at the cutback condition than the approach condition, probably due to the former's larger climb angle and larger angle of attack.

\section{Effects of Surface Liner Treatment}

An acoustic liner is a proven noise reduction technology widely used inside turbofan engines, usually deployed on the engine casing walls. It is known to be very efficient for tone dominated noise field. For the open rotor engines that are tone dominated, there is no engine casing for the treatment, and the amendment for this disadvantage is to utilize the airframe surfaces in the vicinity of the engines for the deployment of the liner treatment. It should be acknowledged up front that this can be a radical and aggressive idea that is against the principle of aerodynamic design; the airframe surfaces are all exposed to external aerodynamic flows and thus are to be designed with minimum drag for aerodynamic efficiency. Currently available liner treatments all induce drag, equivalent to converting smooth surfaces to roughness surfaces, making this concept unfeasible for current applications. Thus, to make liner treatment practical for external airframe surfaces, new technologies will have to be developed for lowdrag or drag-less liners. In this section, the acoustic effects of surface liners are presented, both to demonstrate the acoustic potential of this concept and to quantify the benefits. The latter can hopefully be used to guide the decision making in developing this technology in the future.

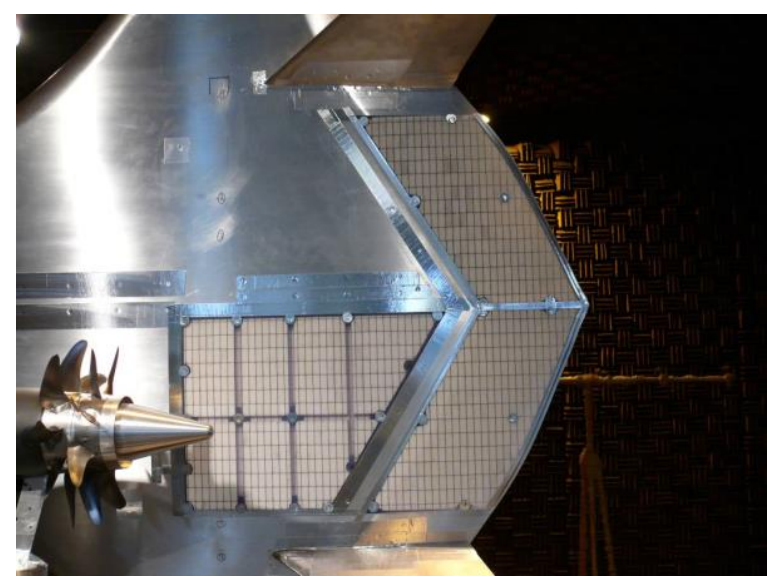

Figure 15. BWB model with local liner treatments.

For the BWB configurations studied here, the engines are located near the BWB trailing edge. Thus, the liner treatment can be deployed in the vicinity of the engines on both the main wings and the elevons. This is illustrated in Figure 15, where the surface areas with grid-like structures are the locations for the liner treatments. To test the noise reduction efficiencies of various liner designs, three types of liner were tested; they are Straight Liner, Hook Liner and Nomex Broadband Liner, all of which were designed by the NASA Langley Liner Technology team specifically for the LSAF open rotor experiment. The liners were designed for peak attenuation of frequencies from $1 \mathrm{BPF}$ to $2 \mathrm{BPF}$. Three engine locations were tested for the acoustic liner, respectively at $1 D, 1.5 D$ and $2 D$ from the BWB trailing edge, the first being the baseline configuration. These relatively large distances from the engines to the BWB trailing edge allow sufficient space for the interactions between the sound waves and the treated surfaces; obviously, if the engines are very close to the trailing edge, the sound waves can mostly propagate directly from the rotors to the far field without interacting with the surfaces, rendering the liner treatment ineffective. For all the cases, the V1 vertical tails are installed at 120 degrees for the liner tests. This is a necessary design choice when considering surface treatment, because without the verticals, the waves impinging on the airframe surface would be 
reflected upwards, becoming irrelevant to the noise on the ground. In other words, the potential effects of the surface liner can be expected to be confined only to the sound waves that also hit the verticals.

The results for the EPNL for the configurations with the surface liner treatment are shown in Table 10, for the three noise certification conditions, as well as the cumulative levels and their margins to the Stage 4 limit. For comparison, a reference configuration is also included in the table for each engine location. These are configurations without the verticals and the liner treatment. Since the cases with liner and verticals were tested only for rotors located off the centerline of the BWB airframe, the EPNL calculations for the configurations in the table, including the reference configurations, only use the data for off-center engine locations, even though the BWB design has one of its three engines on the centerline. This is also why the reference case for the $1 D$ engine location is different from the baseline configuration defined in previous sections; the two have the same aircraft and engine configuration but use different shielding data for the center engine. To clearly reveal the effects of surface liners, it would need references with exactly the same design except for the liner. Unfortunately, the LSAF test database does not have such references, except for the case of $1 D$ engine location, and hence, the liner effects will have to be studied together with those due to the verticals.

Table 10 EPNL (dB) for configurations with acoustic liner on BWB surface.

\begin{tabular}{c|cccccc}
\hline $\begin{array}{c}\text { Engine } \\
\text { Location }\end{array}$ & $\begin{array}{c}\text { Liner } \\
\text { Configuration }\end{array}$ & Approach & Cutback & Sideline & CUM & $\begin{array}{c}\text { Margin to } \\
\text { Stage 4 }\end{array}$ \\
\hline \multirow{6}{*}{$1 D$} & Straight Liner & 94.1 & 85.2 & 88.6 & 267.8 & 26.1 \\
& Hook Liner & 94.0 & 85.3 & 88.6 & 267.9 & 26.1 \\
& Nomex Liner & 94.0 & 85.4 & 88.1 & 267.5 & 26.4 \\
& Reference & 94.4 & 85.5 & 88.7 & 268.6 & 25.3 \\
\hline \multirow{5}{*}{$1.5 D$} & Straight Liner & 93.5 & 82.3 & 86.1 & 261.9 & 32.0 \\
& Hook Liner & 93.5 & 82.3 & 86.2 & 261.9 & 32.0 \\
& Nomex Liner & 93.4 & 82.0 & 86.4 & 261.8 & 32.1 \\
& Reference & 93.4 & 81.9 & 87.2 & 262.5 & 31.4 \\
\hline \multirow{5}{*}{$2 D$} & Straight Liner & 93.2 & 80.5 & 86.9 & 260.7 & 33.2 \\
& Hook Liner & 93.2 & 80.5 & 87.3 & 261.1 & 32.9 \\
& Nomex Liner & 93.3 & 80.9 & 87.0 & 261.2 & 32.7 \\
& Reference & 93.2 & 79.3 & 85.9 & 258.3 & 35.6 \\
\hline
\end{tabular}

From the results shown in Table 10, the combined effects of the surface liner and the vertical tails can be more clearly revealed by subtracting the results of the reference cases from the EPNL results, as shown in Table 11 in which negative numbers indicate noise reduction from the reference case while positive numbers are for noise increase. It can be seen from the table that the overall trends with various liner types are consistent with only small variations between the liner types for a fixed configuration. This consistency manifests itself not only in the cumulative values, but also in the result at each certification conditions, which can also be considered as a repeatability test to ensure the results are reliable, especially important for the cases discussed here since the effects are so small. The variations with the engine location, however, reveal some more complex trends. For the cumulative effects shown in the last column in the table, the $1 D$ engine location seems to have the largest noise reduction, an average value of $-0.9 \mathrm{~dB}$. This reduction is cut by one third when the engines move to the $1.5 \mathrm{D}$ location, and the reduction becomes a noise increase of $2.6 \mathrm{~dB}$ when the engines move further upstream to the $2 D$ location. By examining the individual conditions listed in the table, it can be seen that this trend is followed by the results for approach and cutback conditions, with different amounts in the variations. This trend is probably dictated by the megaphone phenomenon discussed earlier with the vertical tails; as the engines move further upstream, the equivalent megaphone length increases, leading to more focused radiation in the flyover plane. The results for the sideline conditions show very different trends; the noise reduction increases initially as the engines move upstream, but the reduction becomes noise increase at the most upstream location. It can be noted that both the vertical tails and the surface liner are supposed to work mainly for the sideline conditions. The success of the combination of the two, however, depends on the relative positions between the engines, the verticals, and the treated surface areas, which not only set the shielding angles in the far field, but also determine the angles at which the sound waves impinge on the liner surfaces. The latter is known to be an important parameter for the effectiveness of the noise 
absorption by the liner. The complex behavior of the noise reduction effects for the sideline conditions shown in Table 11 may imply the existence of an optimal combination of the engine location, the vertical tail deployment and the surface liner treatment for maximum noise reduction. Clearly, additional data and prediction methods would be helpful.

Table 11 Effects of acoustic liner and verticals in $\Delta \mathrm{dB}$ from the reference configuration.

\begin{tabular}{c|ccccc}
\hline $\begin{array}{c}\text { Engine } \\
\text { Location }\end{array}$ & $\begin{array}{c}\text { Liner } \\
\text { Configuration }\end{array}$ & Approach & Cutback & Sideline & Cumulative \\
\hline \multirow{3}{*}{$1 D$} & Straight Liner & -0.3 & -0.3 & -0.1 & -0.8 \\
& Hook Liner & -0.4 & -0.2 & -0.1 & -0.8 \\
& Nomex Liner & -0.4 & -0.1 & -0.6 & -1.1 \\
\hline \multirow{3}{*}{$1.5 D$} & Straight Liner & 0.0 & 0.4 & -1.1 & -0.6 \\
& Hook Liner & 0.0 & 0.4 & -1.0 & -0.5 \\
& Nomex Liner & -0.1 & 0.2 & -0.7 & -0.7 \\
\hline \multirow{3}{*}{$2 D$} & Straight Liner & 0.1 & 1.3 & 1.0 & 2.3 \\
& Hook Liner & 0.1 & 1.3 & 1.4 & 2.7 \\
& Nomex Liner & 0.1 & 1.6 & 1.1 & 2.8 \\
\hline
\end{tabular}

\section{Conclusions}

This paper has presented a detailed assessment of the noise levels for a BWB aircraft design powered by open rotor engines, including the design characteristics of the baseline configuration with considerations of practical feasibility and emerging technologies, the component noise levels, the methodologies for the acoustic assessment, and the analysis and discussions of the results. It has been shown that though the benefits of the BWB noise shielding lead to a comfortable margin in total aircraft noise levels to current and potential future aircraft noise regulations, about $24 \mathrm{~dB}$ below the current regulation of Stage 4 for the baseline configuration, the design will likely face stiff competitions from conventional aircraft designs, which already have about $16 \mathrm{~dB}$ margin to Stage 4 for aircraft currently in service with comparable size, and which can be expected to increase their noise margin for future configurations with advanced turbofan engines and advanced high lift systems.

By detailed component analysis, it has been shown that the noise levels of the baseline BWB design are held up by the main landing gear noise and the inherently high levels of open rotor noise. The former is due to the exposure of the main landing gears to high speed flows at the junction between the BWB center body and its outer wings, which significantly increases the gear noise and represents a major disadvantage of the BWB design, regardless of the engine type. For the latter, the open rotor source noise is significantly reduced with airframe shielding, but the shielding effects are limited by the engine location within about one rotor diameter from the BWB trailing edge, a practical and critical design constraint that ensures the aerodynamic-propulsion integration. These issues are also the reasons why this baseline configuration does not meet the NASA N+2 noise goal of 42 dB below Stage 4.

To identify the potential for further noise reduction, various parametric studies have also been presented, including engine locations that may enhance the shielding effects, vertical tails that may be optimized for sideline noise reduction, and surface liner treatment for possible sound attenuation. It has been shown that some of these concepts have the potential of further noise reduction, and discussions have been presented for the practical feasibility of the concepts and the significant challenges in bringing these concepts into reality.

\section{Acknowledgments}

The authors thank the NASA Environmentally Responsible Aviation Project, Dr. Fay Collier, Project Manager, for funding this research.

\section{References}

1. Ffowcs Williams J. E. \& Guo Y. P. "Sound Generated from the Interaction of a Steady Flow by a Supersonically Moving Aerofoil," Journal of Fluid Mechanics 195, 113-135, 1988.

2. Guo Y. P. "A Note on Sound from the Interaction of a Cylindrical Flow by a Semi-Infinite Aerofoil of Subsonic Speed," Journal of Sound Vibration. 128(2), 275-286, 1989. 
3. Guo Y. P. "Sound Generation by a Supersonic Aerofoil Cutting through a Steady Jet Flow," Journal of Fluid Mechanics 216, 193-212, 1990.

4. Van Zante, D.E., "The NASA Environmentally Responsible Aviation Project / General Electric Open Rotor Test Campaign," AIAA Paper 2013-415, January, 2013.

5. Clark L. R. \& Gerhold C. H. "Inlet Noise Reduction by Shielding for the Blended Wing Body Airplane," AIAA Paper 99-1937, presented at the 5th AIAA/CEAS Aeroacoustics Conference, Seattle, WA, 1999.

6. Hill G. A., Brown S. A., Geiselhart K. A. \& Burg C. M. "Integration of Propulsion Airframe Aeroacoustic Technologies and Design Concepts for a Quiet Blended Wing Body Transport," AIAA Paper 2004-6306, 2004.

7. Reimann C. A., Tinetti A. F. \& Dunn M. H. "Noise Scattering by the Blended Wing Body Airplane: Measurements and Prediction," AIAA Paper 2006-2474, presented at the 12th AIAA/CEAS Aeroacoustics Conference, Cambridge, MA, 2006.

8. Thomas R. H., Burley C. L. \& Olson E. D., "Hybrid Wing Body Aircraft System Noise Assessment with Propulsion Airframe Aeroacoustic Experiments," International Journal of Aeroacoustics, Vol. 11 (3+4), pp. 369-410, 2012.

9. Czech M. J., Thomas R. H. \& Elkoby R., "Propulsion Airframe Aeroacoustic Integration Effects of a Hybrid Wing Body Aircraft Configuration," International Journal of Aeroacoustics, Vol. 11 (3+4), pp. 335-368, 2012.

10. Bonet J. T., Schellenger H. G., Rawdon B. K., Elmer K. R., Wakayama S. R., Brown D. \& Guo Y. P. "Environmentally Responsible Aviation (ERA) Project - N+2 Advanced Vehicle Concepts Study and Conceptual Design of Subscale Test Vehicle (STV)," NASA Contract NND11AG03C Report, December 2011.

11. Lighthill M. J. "On Sound Generated Aerodynamically I. General Theory" Proceedings of the Royal Society of London A211, 564-587, 1952.

12. Thomas, R.H., Burley, C.L., Lopes, L.V., Bahr, C.J., Gern, F.H., and Van Zante, D. E., "System Noise Assessment and the Potential for a Low Noise Hybrid Wing Body Aircraft with Open Rotor Propulsion", 52nd Aerospace Sciences Conference (National Harbor, MD), American Institute of Aeronautics and Astronautics, Reston, VA, 2014, (submitted for publication).

13. Imamura T., Ura H., Yokokawa Y. Enomoto S., Yamamoto K. \& Hirai T. "Designing of Slat Cove Filler as a Noise Reduction Devices for Leading-Edge Slat” AIAA 2007-3473.

14. Guo Y. P. “A Discrete Vortex Model for Slat Noise Prediction” AIAA Paper 2001-2157, 2001.

15. Guo Y. P. \& Joshi M. C. "Noise Characteristics of Aircraft High Lift Systems" AIAA Journal 41(7), 1247-1256, 2003.

16. Guo Y. P. "On Noise Reduction by Flap Side Edge Fences” Journal of Sound and Vibration 277, 369-390, 2004.

17. Hutcheson F. V., Brooks T. F. \& Humphreys W. M. "Noise Radiation from a Continuous Mold-Line Link Flap Configuration" AIAA 2008-2966, 2008.

18. Ravetta P. A., Burdisso R. A., Ng W. F., Khorrami M. R. \& Stoker R. W. "Screening of Potential Noise Control Devices at Virginia Tech for QTD II Flight Test” AIAA 2007-3455, 2007.

19. Dobrzynski W., Chow L. C., Smith M., Boillot A., Dereure O. \& Molin N. "Experimental Assessment of Low Noise Landing Gear Component Design" AIAA Paper 2009-3276, 2009.

20. Dobrzynski W., Chow L. C., Guion P. \& Shiells D "Research into Landing Gear Airframe Noise Reduction" AIAA 2002-2409, 2002.

21. Guo Y. P. "A statistical model for landing gear noise prediction" Journal of Sound and Vibration 282, 61-87, 2004.

22. Guo Y. P. "A component-based model for aircraft landing gear noise prediction" Journal of Sound Vibration 312, 801-820, 2008.

23. Guo Y. P. "On Trailing Edge Noise Modeling and Prediction for Aircraft High Lift Wings" NASA Contract Report NASA Contract NNL07AA03A, 2010.

24. Guo Y. P. "Slat Noise Modeling and Prediction” Journal of Sound Vibration. 331, 3567-3586, 2012.

25. Guo Y. P., Brusniak L., Czech M. \& Thomas R. H. "Hybrid Wing Body (HWB) Slat Noise Analysis," AIAA Paper 2013-462, 2013.

26. Guo Y. P. "A Study on Local Flow Variations for Landing Gear Noise Research" AIAA Paper 2008-2915, 2008.

27. Guo Y. P. "Effects of Local Flow Variations on Landing Gear Noise Prediction and Analysis" Journal of Aircraft 47, 383-391, 2010.

28. Czech M., and Thomas, R.H., "Open Rotor Aeroacoustic Installation Effects for Conventional and Unconventional Airframes," $19^{\text {th }}$ AIAA/CEAS Aeroacoustics Conference (Berlin, Germany), American Institute of Aeronautics and Astronautics, Reston, VA, 2013. 
29. Guo Y. P., Czech M. \& Thomas R. H. "Open Rotor Noise Shielding by Blended-Wing-Body Aircraft," SciTech 2015, American Institute of Aeronautics and Astronautics, (submitted for presentation). 